\title{
The Consistency, Extent, and Locations of Early-Onset Changes in Cortical Nerve Dominance Aggregates Following Injury of Nerves to Primate Hands
}

\author{
Russ C. Kolarik, Sandra K. Rasey, and John T. Wall \\ Department of Anatomy, Medical College of Ohio, Toledo, Ohio 43699
}

The somatosensory cortex of primates contains patch- and bandlike aggregates of neurons that are dominantly activated by cutaneous inputs from the radial, median, and ulnar nerves to the hand. In the present study, the area $3 b$ hand cortex of adult monkeys was mapped immediately before and after combined median and ulnar nerve transection to evaluate the consistency, extent, and location of early postinjury alterations in the deprived median and ulnar nerve cortical bands. Several alterations were observed acutely after injury. (1) The patchlike cortical aggregates of intact radial nerve inputs from the hand underwent a two- to threefold expansion. This expansion was not related to peripheral changes in the radial nerve skin territory, but was due to rapid central decompression of radial nerve dominance patches. (2) The largest changes involved patches in lateral to central locations of the hand map. (3) The expanded patches occupied cortical zones that were activated by inputs from the digits, palm, and posterior hand prior to injury. These receptive field shifts were initiated within minutes after injury. (4) Receptive fields of neurons within expanded radial nerve patches were normal in size. (5) Besides changes involving radial nerve inputs from the hand, there was a small expansion of forelimb inputs into the preinjury hand cortex; however, the representation of face inputs did not expand into this cortex. (6) Finally, neurons across $50-69 \%$ of the hand cortex were unresponsive to tactile stimuli acutely after this injury. These findings indicate that the distribution patterns of nerve dominance aggregates in adult primates begin changing within minutes after nerve injury. Cortical changes involving specific inputs occupy similar extents and locations of cortex, and are arranged in highly consistent patterns, in different individuals. It is suggested that this consistency reflects specific patterns of central sensitization or disinhibition that are triggered by the injury.

[Key words: primary somatosensory cortex, brain reorganization, acute denervation, cortical map imaging, sensitization, disinhibition]

The primate hand receives mechanoreceptor innervation via the median, ulnar, and radial nerves. Injury of these nerves leads to somatotopic reorganization in the cortical area $3 \mathrm{~b}$ map of the hand (Kaas et al., 1983; Merzenich, 1987; Merzenich et al.,

Received Sept. 21, 1993; revised Dec. 16, 1993; accepted Jan. 13, 1994.

This work was supported by National Institutes of Health Grant NS 21105.

Correspondence should be addressed to Dr. J. T. Wall at the above address.

Copyright (c) 1994 Society for Neuroscience 0270-6474/94/144269-20\$05.00/0
1988, 1990; Wall, 1988; Wall et al., 1990; Kaas, 1991). A major characteristic of this reorganization is that representations of parts of the hand with intact innervation expand, in a somewhat idiosyncratic manner in different individuals, to occupy largerthan-normal cortical spaces.

Because these findings emerged from a perspective that cortical organization of adult primates was not modifiable, investigators have usually attempted to maximize reorganization by allowing considerable time to elapse after injury. Consequently, observations pertaining to changes within the first few minutes to hours after injury are quite limited (see Discussion). The most pertinent data come from monkeys that had undergone acute transection of the median nerve (Merzenich et al., 1983b). These data indicated that the cortical representations of innervated parts of the hand of one monkey underwent little or no immediate reorganization, whereas cortical representations in two other monkeys underwent expansions that, although not quantitated, were clearly noticeable. These expansions were delimited to the parts of the hand map where digits were normally represented. These results suggested that (1) neurons in some areas of the cortical map lose cutaneous responsiveness immediately after injury, and (2) neurons in other areas of the map, particularly digit representations, can become responsive to intact inputs soon after injury.

Several issues remain unresolved by these findings. First, given the variability in the incidence of expansion across the small number of monkeys studied, it is difficult to know whether rapid cortical expansion consistently occurs in different individuals. Second, because there was no quantitation of cortical areas that expanded, it is difficult to gauge what extent of reorganization seen chronically occurs soon after injury. Finally, given that all observations followed injury of the median nerve, it is unclear whether the delimitation of expansions to normal digit zones resulted from this particular injury or, alternatively, whether there are nonuniformities in reorganization potential in different cortical zones. These uncertainties concerning the consistency, extent, and potential locales of early cortical changes prompted the first three questions of the present study. First, is rapid expansion of cortical area $3 b$ representations a consistent consequence of hand nerve injury, or does such expansion occur in some individuals but not others? Second, when rapid expansion occurs, what is the extent of this change? Third, are cortical changes delimited to particular zones of the hand map, or do all cortical locales have an equal potential for undergoing early expansion?

To address these questions, we utilized recent findings indicating that the median, ulnar, and radial nerves normally pro- 
vide dominant inputs to band- and patchlike aggregates of neurons in the cortical area $3 b$ hand map (Wall et al., 1993). The cortical bands activated by low-threshold inputs from the median and ulnar nerves normally occupy a major fraction of the hand map, whereas inputs from the radial nerve activate patches involving only a small fraction (about 12\%) of the map. In the present study, the median and ulnar nerves were acutely transected, and the properties of the remaining radial nerve dominance patches were compared to normal radial nerve patches. Since combincd injury of these nerves produces both a major denervation of the hand, and extensive input deprivation in the cortical hand map, we further wondered whether neurons in the hand map become responsive to forelimb or face inputs, both of which activate cortical zones directly adjacent to the hand map. This prompted the final question: acutely following this major injury, does the hand cortex become responsive to nonhand inputs from the forelimb and face?

\section{Materials and Methods}

The 14 adult monkeys contributing to this study were treated in accordance with the NIH Guide for the Care and Use of Laboratory An$\mathrm{imals}$. During all surgical and recording procedures, monkeys were anesthetized and tranquilized with ketamine hydrochloride $(25-50 \mathrm{mg} / \mathrm{kg})$ and acepromazine $(0.4-0.8 \mathrm{mg} / \mathrm{kg})$ given intramuscularly at $1-2 \mathrm{hr}$ intervals.

Experimental sample. Recordings were made immediately before and after transection of the median and ulnar nerves in five squirrel monkeys (Saimiri sciureus) and three marmoset monkeys (Callithrix jacchus). The area $3 \mathrm{~b}$ hand cortex was completely mapped following injury in five monkeys (four squirrel, one marmoset) to assess the extent of cortical changes. In the remaining three monkeys (one squirrel, two marmoset), postinjury recordings were focused around delimited cortical regions that, prior to injury, bordered zones with radial nerve inputs. Data from these eight monkeys were compared to data obtained with identical procedures from three normal squirrel and three normal marmoset monkeys (see Wall et al., 1992a, 1993).

Experimental sequence. It was expected that median and ulnar nerve transection would produce a major loss of input signals normally used to identify the area $3 b$ hand cortex. Therefore, preinjury mapping was carried out in each monkey to localize this cortex unambiguously. Attention was devoted to carefully bracketing the medial and lateral borders between the hand map, and adjacent forelimb and face representations. Additional mapping of lower density was done to define roughly the internal somatotopic organization within the hand cortex. Thus, the experimental sequence in each monkey entailed (1) preinjury mapping, (2) transecting both nerves, and (3) remapping the hand cortex as delineated prior to injury. Postinjury organization was studied from $5 \mathrm{~min}$ to $10 \mathrm{hr}$ after injury.

Nerve transection. An incision was made across the forearm, the median and ulnar nerves were localized proximal to the wrist, and a loop of suture was passed beneath each nerve. The skin incision was closed except for an opening for each suture loop. Both nerves were subsequently transected simultaneously by pulling the loops and cutting the nerves with scissors. The hand was not stimulated between the time of injury and the subsequent first recordings.

Stimulation. Stimuli and criteria for defining receptive fields have been described previously (e.g., Wall et al., 1992a, 1993). Stimuli consisted of hand-delivered contacts and brushes of the skin, hairs, or decp tissues. Cutaneous stimuli were presented so as to monitor activity from receptors directly beneath the probe, rather than receptors affected by gross spread of stimuli across the skin. Receptive fields were defined as the total skin area from which neuronal discharges were elicited to the employed cutaneous stimuli. These fields were judged to reflect maximal receptive field areas.

Recording. The mapping procedures have been described (Wall et al., 1992a, 1993). In brief, the head was positioned in a frame and the parietal cortex was exposed and photographed at 30-40× magnification. An array of recordings was made across the area $3 \mathbf{b}$ hand and adjacent cortex. With some variance due to vasculature, efforts were made to space recording sites at $200-300 \mu \mathrm{m}$ intervals (preinjury mapping was less dense). Recordings were made with tungsten microelectrodes $(1-4$
$\mathrm{M} \Omega$ at $1 \mathrm{kHz}$ ), oriented perpendicular to the cortical surface. The location of each recording site was marked on the cortical photograph. At each penetration, attempts were made to define a low-threshold receptive ficld from multiple-unit discharges. Responses used for receptive field determination were usually recorded $400-900 \mu \mathrm{m}$ below the surface; however, responses at other depths typically had a similar receptive field. In penetrations where no cutaneous responses were observed, efforts were made to stimulate wide regions of the body surface as the electrode was advanced into, and withdrawn from, depths below those that were normally responsive. As a control procedure during mapping, the investigator defining receptive fields neither saw the brain photograph, nor knew the location of the microelectrode. Although efforts were not made to evaluate responsivity quantitatively, during mapping we noticed no qualitative changes in background activity or gencral responsivity of recorded neurons.

Data analysis. Following mapping, selected cortical sites were marked, and the monkeys were overdosed and perfused. Postmortem dissections were done to confirm identification of transected and intact nerves. The parietal cortex was sectioned frozen, and cresyl violet-stained sections were used to localize the marked sites and cytoarchitectonic borders of area $3 b$.

In each monkey with a complete postinjury map, the innervation territory of the intact radial nerve was estimated by summing all area $3 b$ receptive fields on the hand. Area measures were made of this skin territory. To measure around contours of the hand, an incision was made around the perimeter of the hand, and the glabrous and posterior surfaces were dissected as two pieces. These pieces were laid on glass slides. The edges of each piece, and the borders of the radial nerve tcrritory were traced onto the slides, and measured with a planimeter.

Cortical data were evaluated using previously described procedures (Wall et al., 1986, 1992a, 1993). In brief, the rostral and caudal borders of area $3 \mathrm{~b}$ were determined cytoarchitectonically, and the mediolateral extent of the hand map was determined from the preinjury borders with the adjacent face and forelimb representations. To delimit cortical areas with different receptive field or activation properties, the response of each recording site was labeled. Borders delimiting cortical sites with similar properties (e.g., skin input, unresponsive) were placed midway between adjacent sites that did and did not have that property. If a receptive field straddled two input sources that were being distinguished, the border between the cortical representations of the two sources was placed at the penetration location. Cortical representations were measured with a planimeter.

To providc a measurc of the degree of skin-to-cortex scaling in the size of radial nerve territories, the measured skin and cortical areas were used to determine a "compression factor," calculated from the ratio of skin area $\left(\mathrm{mm}^{2}\right)$ : cortical area $\left(\mathrm{mm}^{2}\right)$. Small to large compression factors indicated a smaller to larger compression of skin onto cortical area.

\section{Results}

\section{Preinjury organization}

It was difficult to predict if the area $3 \mathrm{~b}$ hand map would be easily localized after loss of median and ulnar nerve inputs. To overcome this potential difficulty, initial mapping was carried out before injury in each monkey to assure accurate delineation of the normal area $3 \mathbf{b}$ hand cortex. Three preinjury results provide information pertinent for interpreting the postinjury findings. First, although attempts were not made to define somatotopy comprehensively, the somatotopic features that were apparent approximated the organization previously reported for area $3 \mathrm{~b}$ hand maps in normal squirrel and marmoset monkeys (e.g., Merzenich et al., 1987; Wall et al., 1992a, 1993). For example, neurons at all recording sites were cutaneously responsive, with inputs from glabrous digits represented anteriorly, inputs from palmar pads posteriorly, and inputs from hairy skin in scattered locations (e.g., Fig. $1 A, B$ ). Normal lateral to medial sequences in the representations of digits were apparent (Fig. $1 A-D$ ), and the preinjury sizes of hand maps were normal (Fig. $1 E, F)$. Finally, although preinjury responses were not sampled systematically from all hand locations, receptive fields were 


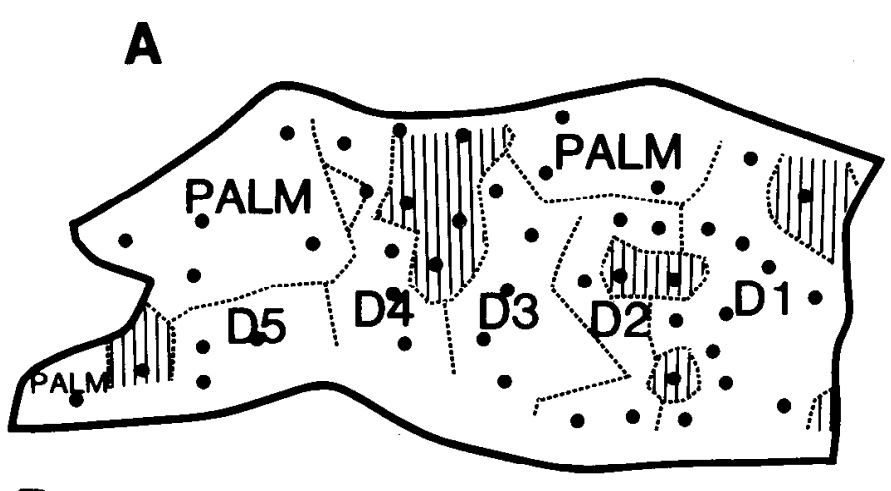

B
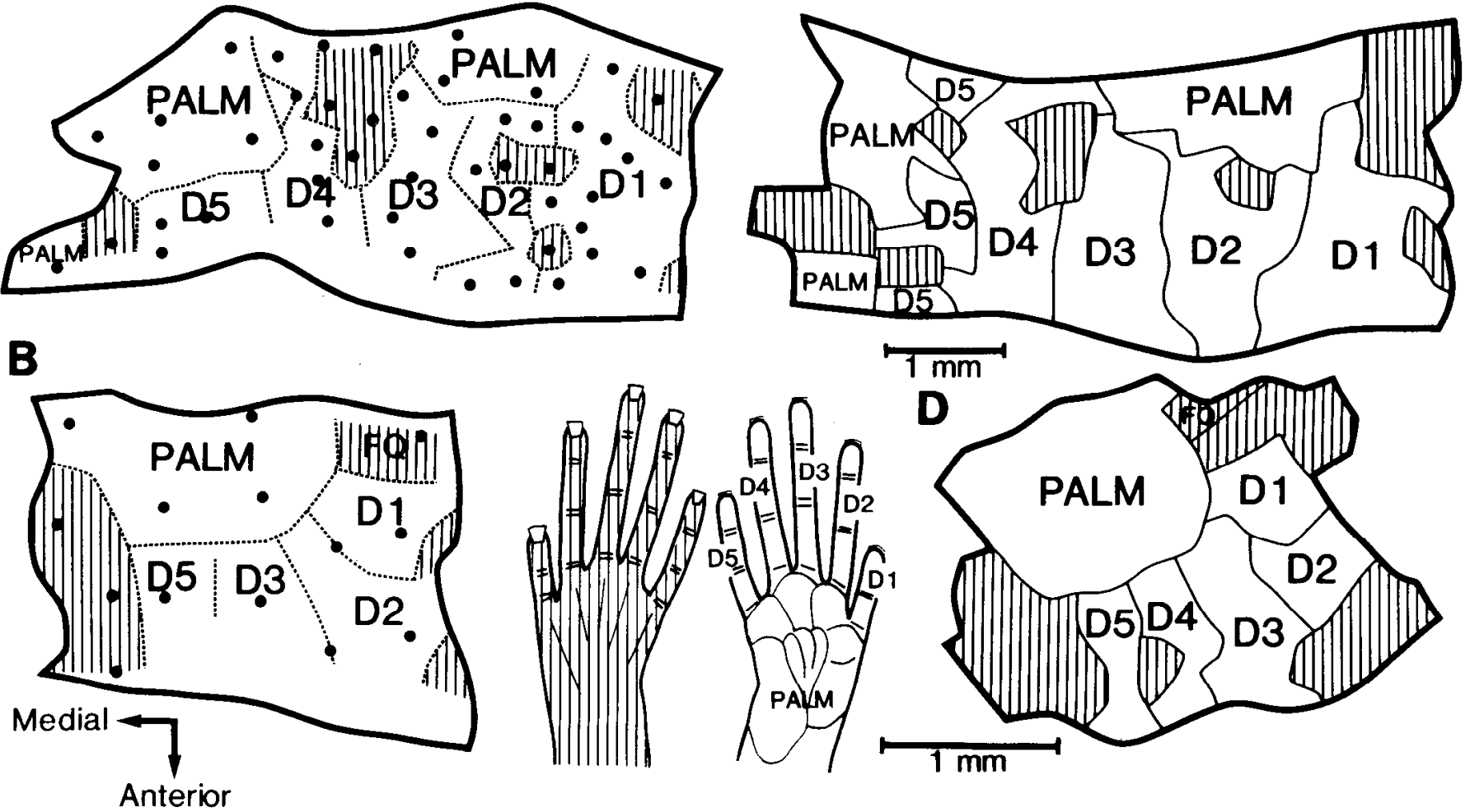

Anterior
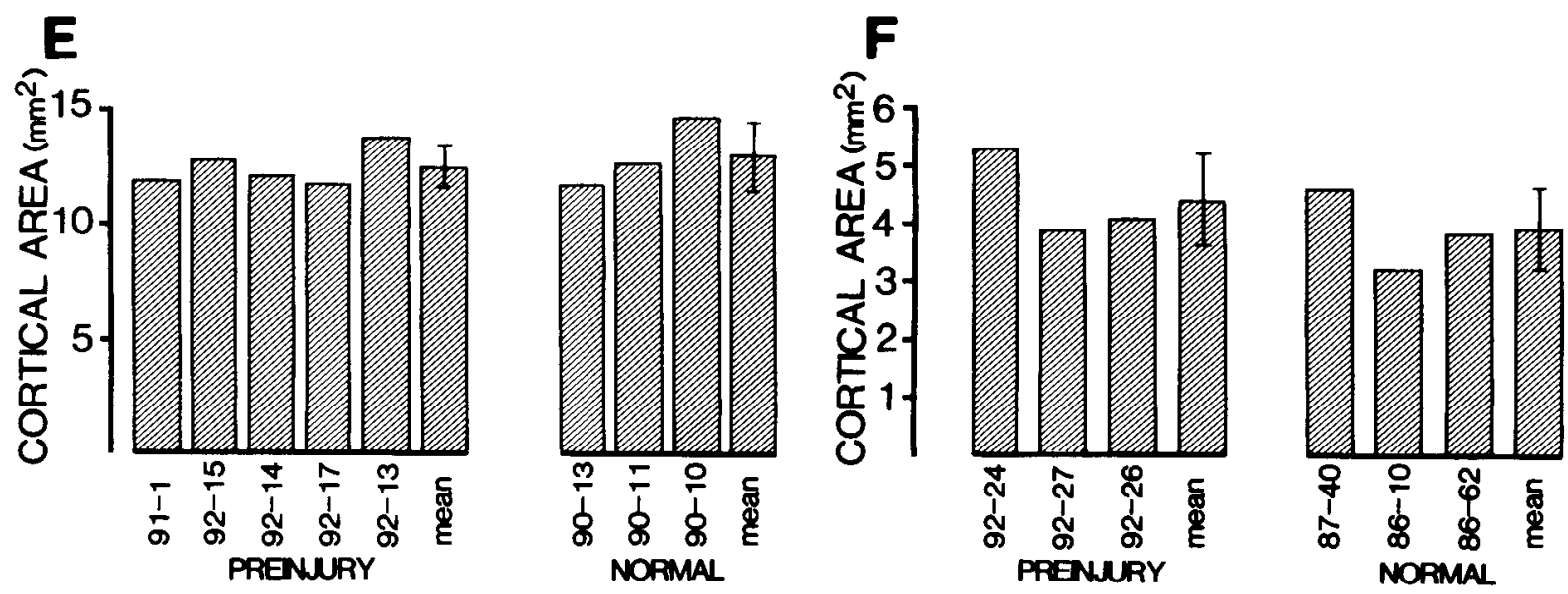

Figure 1. Low-density mapping was carried out in each monkey immediately before nerve section to define the extent and general somatotopy of the hand cortex as it existed before injury. Examples of preinjury organization in a squirrel $(A)$ and marmoset $(B)$ monkey are shown. Dots indicate recording sites within the area $3 \mathrm{~b}$ hand cortex; additional sites defining medial-lateral borders are not shown. The organization in the area $3 \mathrm{~b}$ hand cortex as determined by high-density maps from a normal squirrel $(C)$ and marmoset $(D)$ monkey are also shown for comparison. Note that the relative locations of recording sites with receptive fields on glabrous digits, palm, and hairy hand in $A$ and $B$ approximate the somatotopic organization seen in more extensive maps from normal monkeys (e.g., $C$ and $D$ ). Abbreviations and conventions: D1-D5, digits 1 (thumb) through 5 (little finger); $F Q$, forequarter; white, glabrous skin; hatching, hairy skin. Spatial orientation in $B$ applies to all maps. $E$, Sizes of area $3 b$ hand maps in preinjury (left) and normal (right) squirrel monkeys. End bars show means and SDs for individuals in that group. $F$, Sizes of area $3 b$ hand maps in preinjury (left) and normal (right) marmoset monkeys. End bars show means and SDs for individuals in that group. The areas in marmosets include a representation of the forequarter, which, in normal marmosets, occupies an average of $0.2 \mathrm{~mm}^{2}$. This representation was not demarcated from the hand cortex in preinjury maps and, given its small area, was included as part of the hand map area in both groups. Note that preinjury maps were similar to normal in size [squirrel monkeys: $t(6)=0.676$, NS; marmoset monkeys: $t(4)=0.950$, NS]. Scale bar in $C$ also applies to $A$, and scale bar in $D$ also applies to $B$.

observed for many regions on the hand, and from the innervation territories of all hand nerves, in each monkey (Fig. 2). Thus, preinjury mapping clearly demonstrated the location and extent of the hand map in each monkey; that preinjury orga- nization in the individuals in the present study was consistent with the organization previously seen in normal monkeys; and that, prior to injury, the median, ulnar, and radial nerves provided inputs to the hand cortex in each experimental monkey. 
A

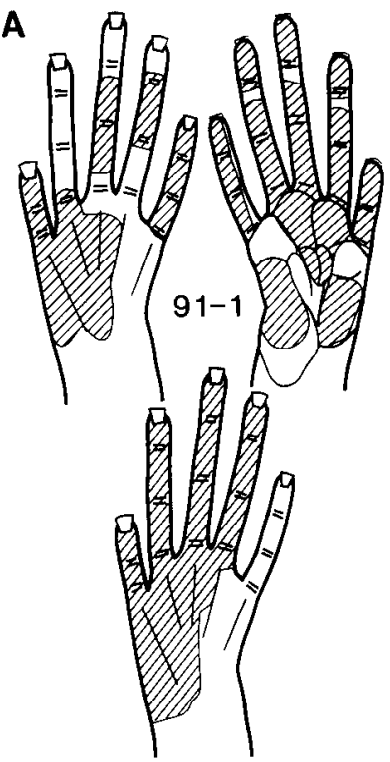

Figure 2. Composite receptive fields of neurons recorded in the area $3 \mathrm{~b}$ hand cortex of four squirrel monkeys $(A-D)$ and one marmoset monkey $(E)$ before and after acute section of the median and ulnar nerves. In $A-E$, hatching on each top pair of hands indicates the receptive field composite from the lowdensity preinjury sample of recording sites, whereas hatching on each bottom hand indicates the composite from a high-density postinjury sampling of recording sites across the entire area $3 \mathrm{~b}$ hand cortex. $F$, Representative innervation territories of the radial, median, and ulnar nerves as determined from peripheral axon recordings in normal monkeys (see Wall et al., 1993). Note that, prior to injury, the composite receptive ficld in cach monkcy extends across the normal innervation territories of all three nerves whereas, after injury, the composite closely approximates the innervation territory of the radial nerve.

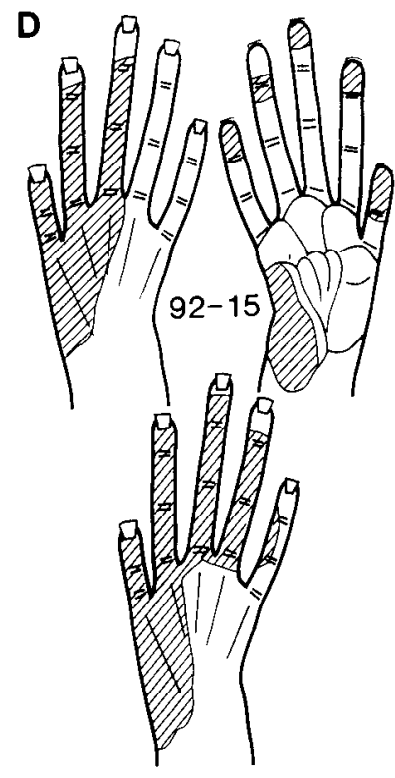

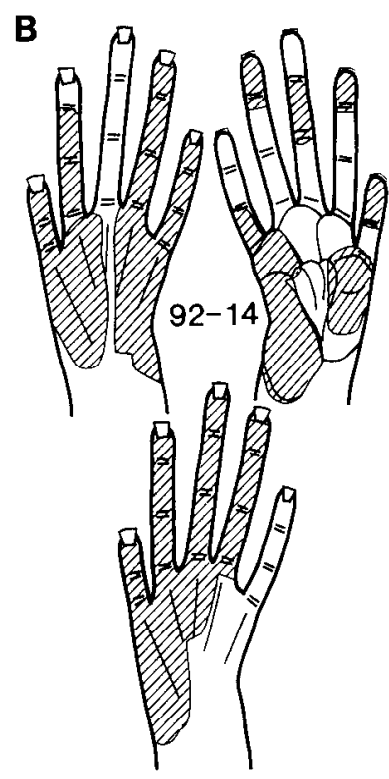

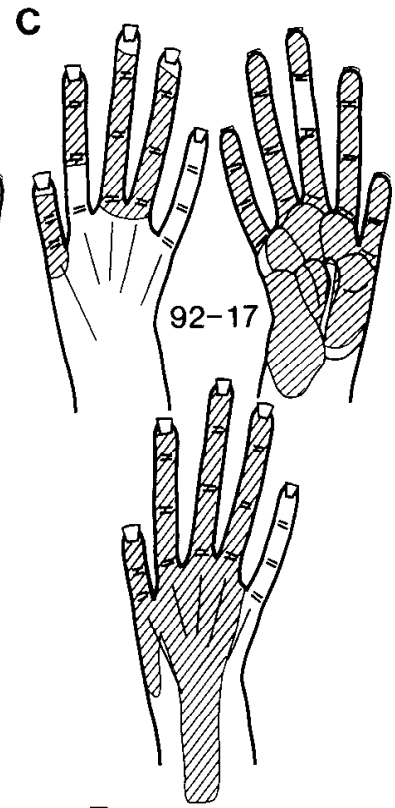

\section{E}

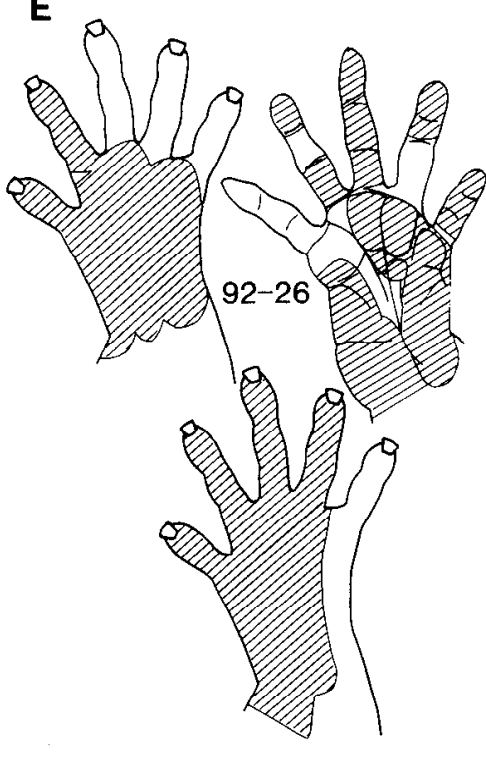

$\mathbf{F}$

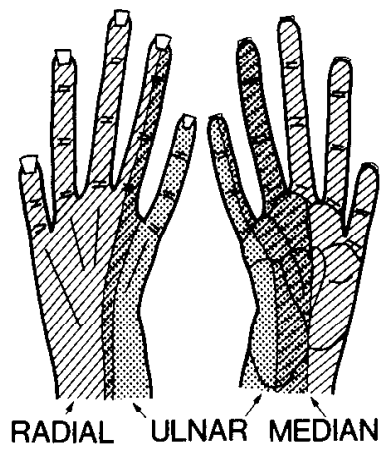

\section{Postinjury organization}

Peripheral innervation. The extent of the hand that retained innervation after injury was estimated by summing the postinjury receptive fields in each monkey in which the entire hand cortex was mapped after injury. With the exception of a dorsal digit 5 receptive field seen at a single cortical recording site (e.g., Fig. $2 D$ ), inputs were consistently missing from the glabrous and ulnar hairy hand following injury (e.g., Fig. $2 A-E$ ). The postinjury territory with residual inputs closely approximated the typical normal radial nerve territory (e.g., Fig. $2 F$ ). Taken together with the postmortem dissections of the nerve stumps and intact nerves (see Materials and Methods), these results demonstrate that postinjury hand inputs were derived from the radial nerve, and not ectopic branches of the median and ulnar nerves.

Distribution and size of the total radial nerve cortical projection. Acutely after injury, radial nerve inputs activated aggre-

gates of neurons in three to six cortical patches that were scattered across the area $3 \mathrm{~b}$ hand cortex (Figs. 3, 4). When summed and expressed as a percentage of the hand cortex, these postinjury patches activated $29-48 \%$ of the hand maps of individual squirrel and marmoset monkeys.

Comparisons to normal squirrel and marmoset monkeys indicated injury did not change the number of radial nerve cortical patches (normal $=4-6$; postinjury $=3-6$ ), but did significantly increase the total cortical area activated by radial nerve inputs (Figs. 3, 4). In squirrel monkeys, a comparison of the four completely mapped postinjury monkeys and three completely mapped normal monkeys indicated an approximate threefold increase in the percentage of the hand cortex activated by radial inputs [Fig. 5, top right; normal mean $=12 \%$; postinjury mean $=37 \% ; t(5)=6.523, p<0.01]$. Comparison of the one completely mapped postinjury marmoset monkey and three completely mapped normal marmoset monkeys indicated about a twofold increase $($ normal mean $=23 \%$; postinjury $=48 \%$ ). Stim- 

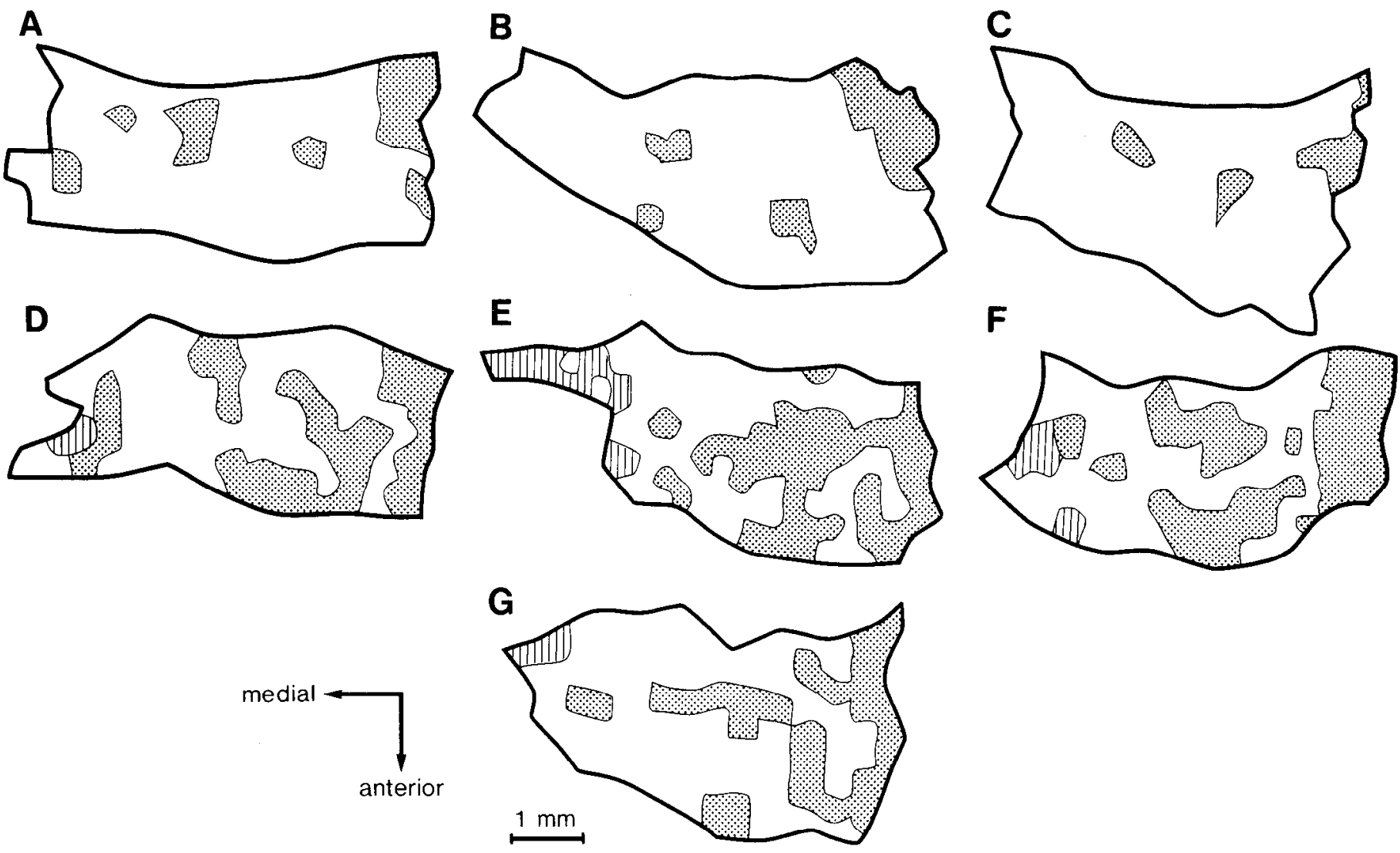

Figure 3. Stippling indicates neuronal aggregates that were activated by radial nerve inputs in the cortical area $3 \mathrm{~b}$ hand maps of three squirrel monkeys that had normal hand nerves $(A-C)$, and four squirrel monkeys that had undergone acute section of the median and ulnar nerves $(D-G)$. Note that (1) functionally expressed inputs from the radial nerve are distributed as a set of discontinuous patches in all maps, and (2) the extent of the hand map with functionally expressed radial nerve inputs is consistently larger than normal in each monkey that had undergone section. In addition, note that small patches of the preinjury hand map became responsive to forearm inputs after injury (hatching). In $D-G$, white areas indicate zones where neurons were unresponsive to cutaneous inputs whereas, in $A-C$, white areas indicate zones with median and ulnar nerve inputs. Scale bar and oricntation apply to all maps.

ulus-evoked responses of neurons within the enlarged territories were initially recorded within $5 \mathrm{~min}$ after injury, and were apparent without any previous hand stimulation.

For squirrel monkeys, where the larger sample allowed further quantitative analyses, postinjury enlargement of the radial nerve cortical representation was not attributable to peripheral differences in either the percentage or absolute area of the hand innervated by the radial nerve [Fig. 5, top left; mean normal radial skin area $=899 \mathrm{~mm}^{2}$; mean postinjury radial skin area $=822$ $\mathrm{mm}^{2} ; t(9)=0.972$, NS]. Instead, the radial nerve cortical expansion involved a change in scaling of inputs from normally sized skin areas. To characterize this change, a "compression factor" was calculated (see Materials and Methods), which indicated the number by which the cortical area would be multiplied to equal its respective skin area. Radial nerve compression factors in normal squirrel monkeys are somewhat variable and large (Fig. 5, bottom; Wall et al., 1993). Following injury, compression factors were decreased below normal levels by a factor of about three (mean normal compression/mean postinjury compression $=609 / 189$ ) $[$ Fig. 5 , bottom; $t(5)=2.67, p<$ $0.05]$. This compression decrease reflects an elevation of the postinjury percentages of the hand cortex activated by radial inputs $(29-41 \%)$ to levels that approximated the postinjury percentages of the hand skin innervated by radial inputs $(33-37 \%$; Fig. 5, top). This contrasts sharply with normal scaling where the percentages of the hand cortex activated by radial inputs $(8-15 \%)$ are roughly one-third the percentage of the hand skin normally innervated by radial inputs (34-40\%; Fig. 5, top). These postinjury compression changes were highly consistent in different individuals (Fig. 5, bottom).

\section{Reorganization of individual patches within the overall radial nerve projection}

Individual radial nerve patches were analyzed to evaluate the locations of cortical changes, and to assess skin-to-cortex relationships of inputs to different patches. In squirrel monkeys, which have larger hand cortices, individual postinjury patches occupied cortical areas ranging from 0.1 to $4.2 \mathrm{~mm}^{2}$, whereas for marmoset monkeys individual patches occupied areas ranging from 0.1 to $1.1 \mathrm{~mm}^{2}$. Following injury, the largest patches were consistently located in more lateral to central locations of the hand map, whereas smaller patches were located medially (e.g., Fig. 6). An overall comparison of cortical patches indicated a postinjury increase in mean patch size in both squirrel monkeys $\left[\right.$ normal $=0.361 \mathrm{~mm}^{2} ;$ postinjury $=0.994 \mathrm{~mm}^{2} ; t(5)=$ $5.329, n<0.011$, and the one marmoset monkey that was completely mapped after injury (normal $=0.161 \mathrm{~mm}^{2}$; postinjury $=0.622 \mathrm{~mm}^{2}$ ). Further analyses indicated an anisotropic pattern of change for patches in different cortical locations. Specifically, the largest postinjury changes involved patches that were cen- 

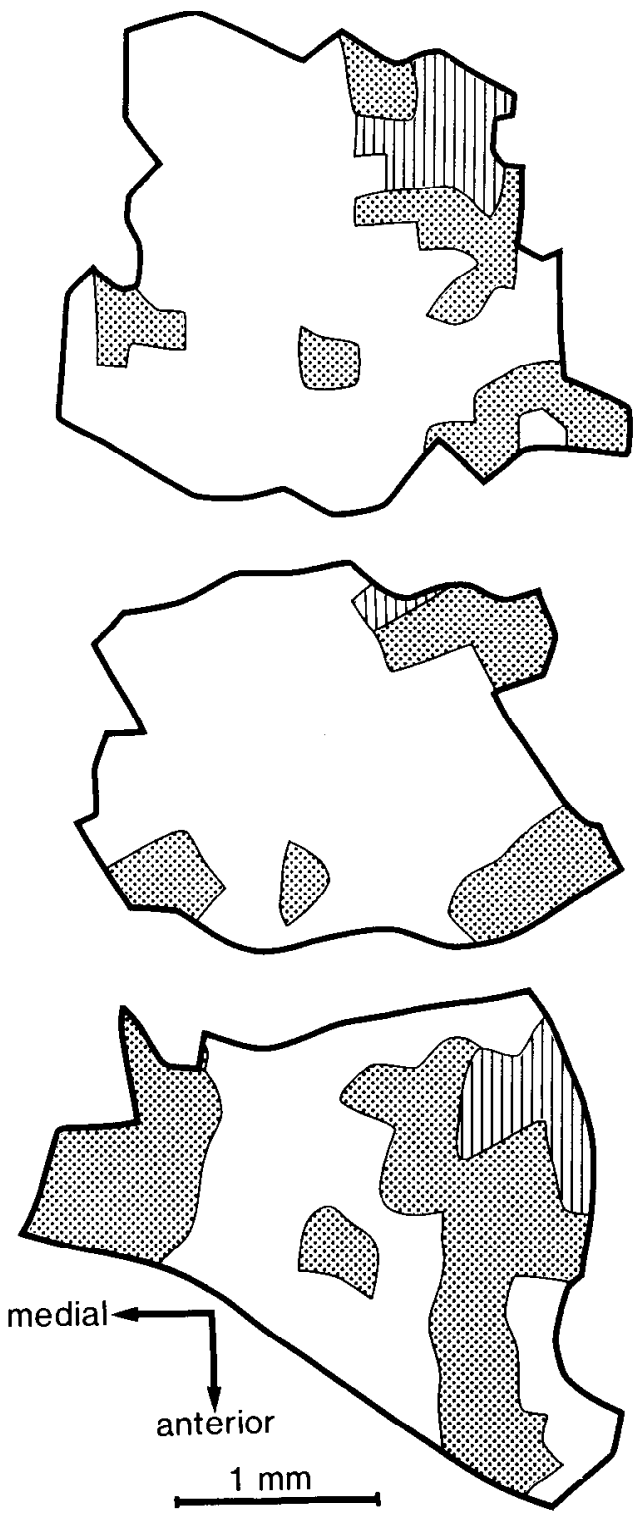

Figure 4. Stippling indicates neuronal aggregates activated by radial nerve inputs in the cortical area $3 b$ hand maps of two marmoset monkeys that had normal hand nerves (top two maps), and one marmoset that had undergone acute section of the median and ulnar nerves (bottom map). Note that functionally expressed inputs from the radial nerve are distributed as a set of discontinuous patches in all maps, and a largerthan-normal percentage of the map has functionally expressed radial nerve inputs acutely after injury. A representation of forequarter inputs that normally borders the posterior-lateral hand map did not undergo enlargement (hatching). Other conventions are as in Figure 3. Scale bar and orientation apply to all maps.

tered within the lateral half or, to some degree, central part of the map, whereas patches centered medially remained small, and did not differ in size from medial patches in normal maps (e.g., Figs. 6, 7). Due to irregularities in the shapes of hand maps, and to the fact that the hand map is narrower in the anterior-posterior direction, it was more difficult to establish rigorously a further pattern of change for anterior-posterior locations. However, some large patches in the lateral half of all postinjury maps spanned the full anterior-posterior extent of the hand map, whereas none of the lateral patches in normal maps spanned this extent (e.g., Fig. 3). This suggests patch ex- pansions involved anterior and posterior locations where inputs from digits, palm, and posterior hand would normally be represented (and see below).

Analyses were performed to evaluate whether these changes in individual cortical patches were related to changes in the skin areas activating individual patches. There was considerable variability in the skin area associated with an individual patch (Figs. 8-10). In both normal and postinjury conditions, skin areas varied from a single digit to larger areas involving multiple digits or the dorsal hand (e.g., Figs. 8, 9). Quantitative comparisons of skin areas associated with normal and postinjury cortical patches indicated no differences in (1) overall ranges in size of skin areas (Fig. 10), (2) overall means of skin area per patch [Fig. 10, bottom, hatched bars; $t(5)=1.622$, NS], (3) mean skin areas associated with medial cortical patches [Fig. 10, bottom, small-dot bars; $t(5)=0.071, \mathrm{NS}$ ], or (4) mean skin areas associated with lateral cortical patches [Fig. 10, bottom, largedot bars; $t(5)=0.397$, NS]. Taken together, these findings indicate that acute injury did not cause individual cortical patches to be accessed by inputs from abnormally sized skin territories.

The above stationarity of skin areas, together with the increased lateral cortical patch size, combined to produce a significant postinjury lowering of the mean compression factors for lateral patches $[t(5)=2.79, p<0.05]$, but not medial patches $[t(5)=1.09$, NS $]$. Each postinjury map contained at least one patch which reflected a lowering of central compression to oncthird to one-tenth of the normal mean compression; for example, the normal mean compression factor/patch $=841$ whereas individual postinjury patches with lowest factors ranged from 80 to 280 per patch (Fig. 11). Thus, the lowering of compression for the total radial nerve projection by a factor of about 3 , as described above, does not reflect heterogeneity in patch changes, and underestimates the extent of larger decompressions in specific cortical locales.

Preinjury inputs to postinjury radial nerve patches. The skin locations that provided preinjury input to neurons in the enlarged postinjury radial nerve patches were assessed with two approaches. The first approach was to sum the receptive fields of all preinjury recording sites that were located within postinjury radial nerve cortical patches. This approach provided a composite of the areas on the hand that provided preinjury inputs to the postinjury radial nerve cortex (e.g., Fig. 12A-C). The second approach was to compare the receptive field locations of preinjury recording sites that were within $0-200 \mu \mathrm{m}$ of a postinjury recording site that had a receptive field on radial nerve skin. This approach provided a peri-injury receptive field comparison for recording sites that were similar in location (e.g., Fig. 12D). Both approaches indicated that neurons in postinjury radial nerve patches were, prior to injury, driven by inputs from a range of hand locations. As might be expected, some preinjury inputs involved skin locations innervated by the radial nerve (e.g., Fig. 12D, fields 1, 2, 7). In contrast, other inputs involved hairy and glabrous skin normally innervated by the median and ulnar nerves (e.g., compare Figs. $2 F, 12 A-C$, and $12 D$, fields $3-$ $6)$. Changes in pre- versus postinjury receptive fields at individual cortical locales varied from little or no shift in fields (e.g., Fig. $12 D$, fieids 1,2 ), to small shifts around the surface of a digit (e.g., Fig. $12 D$, fields $4,6,8$ ), to larger shifts around the surface of the hand (e.g., Fig. $12 D$, fields $3,5,9$ ). These findings indicate that preinjury digit, palm, and posterior hand representations were involved in postinjury reorganization. Receptive field shifts were first sampled within $5 \mathrm{~min}$ after injury. 
Total radial skin
as \% of total hand
- Total radial cortex as

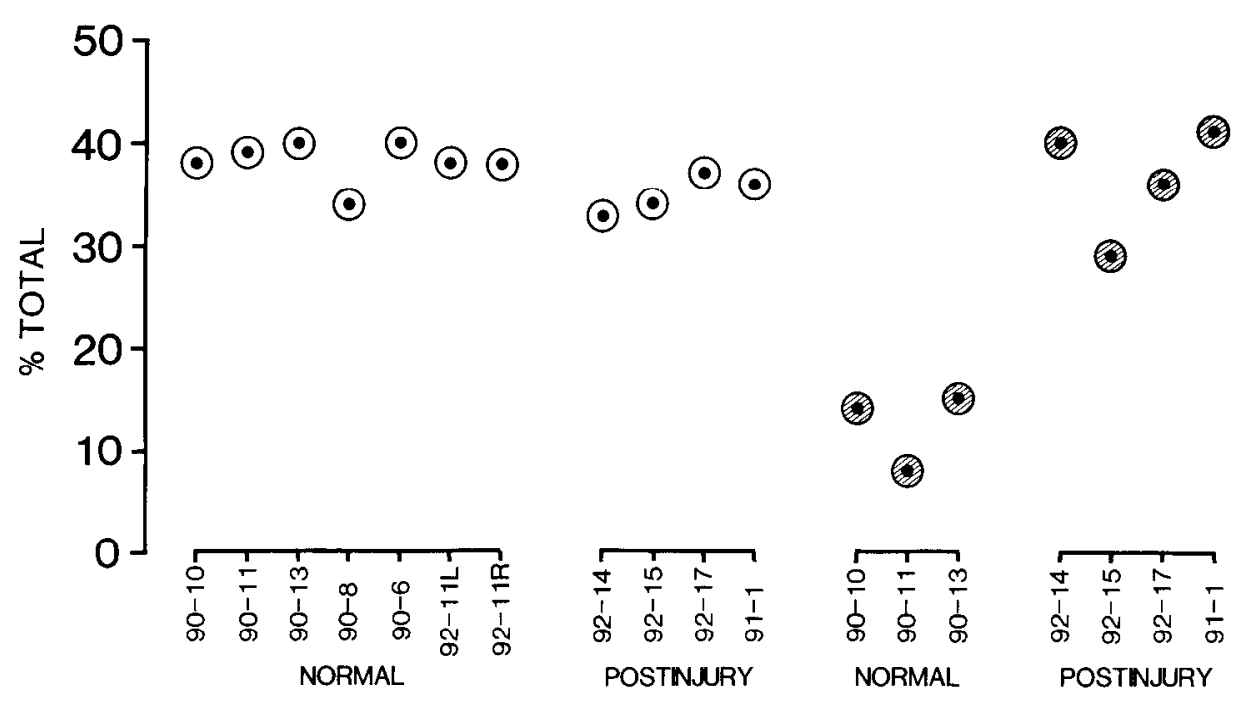

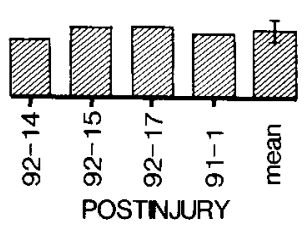

Figure 5. Size analyses of total radial nerve skin and cortex areas. Top left, The percentage of the hand surface related to the radial nerve innervation territory is indicated for the hands of normal and postinjury monkeys. The normal percentages were derived by summing the receptive field areas of axons recorded from the radial nerve in each hand, and then expressing this area as a percentage of the total skin area of that hand (see Wall et al., 1993). Postinjury percentages were derived by summing the receptive ficld arcas of all area $3 b$ neurons that had a receptive field on the hand after acute medianulnar nerve injury (e.g., see Fig. 2), and then expressing this area as a percentage of the total skin area of that hand. Note the similarity in the sizes of the radial nerve territories in normal and postinjury hands. Top right, The percentage of the cortical area $3 \mathrm{~b}$ hand map that contained neurons activated by radial nerve inputs is indicated for normal and postinjury monkeys. Note that postinjury cortical areas were about three times larger than normal. Bottom, Comparison of compression factors ( $\mathrm{mm}^{2}$ radial skin area $/ \mathrm{mm}^{2}$ radial cortical area) for normal and postinjury conditions. In each group, right bars indicate means and SDs of the individuals shown to the left. Note the (1) lowering of compression factors after injury, and (2) consistency in the compression decrease for each postinjury monkey.
They were observed upon the first postinjury stimulation of the hand, and continued to be sampled, with variable degrees of intervening stimulation, up to $10 \mathrm{hr}$ after injury.

Sizes of cortical receptive fields on radial nerve skin. All radial nerve receptive fields recorded at individual recording sites in postinjury maps were compared to all receptive fields that involved radial nerve skin in preinjury and normal monkeys. Postinjury radial nerve fields typically ranged from small fields spanning a fraction of a digit (e.g., Fig. $12 \mathrm{D}$, postinjury fields 2,6 ; Fig. 13, fields $35,45,48$ ), to larger fields spanning one or multiple digits (e.g., Fig. 12D, postinjury fields 1, 4, 8; Fig. 13, fields $36,38,39,42,46,47)$, a combination of digit and dorsal hand (e.g., Fig. 13, fields 33, 40, 41), or the dorsal hand alone (e.g., Fig. $12 D$, postinjury fields 3, 5, 7; Fig. 13, fields 32, 37 , 44). Except for fields on adjacent digits, which were interrupted by interdigit spaces, all fields were continuous (e.g., Fig. 13). In terms of gross size, there were no major differences in postinjury receptive fields, and fields that involved radial nerve skin in preinjury and normal monkeys. For example, similar to postinjury fields, for both preinjury and normal conditions, radial nerve fields typically ranged from small fields spanning a fraction of a digit (e.g., Fig. 13, fields 4, 16, 19, 20, 27) to larger fields spanning one or multiple digits (e.g., Fig. 13, fields 5, 8, $12,24,26,31$ ), a combination of digit and dorsal hand (e.g.,
Fig. 13, fields 2, 7, 14), or the dorsal hand alone (e.g., Fig. 13, fields $3,6,10,13,15)$. In addition, there were no systematic differences in the sizes of fields within particular subregions of the radial nerve territory when postinjury fields were compared to normal and preinjury fields (e.g., Fig. 13: compare 32, 37 vs $6,10,18,25$; compare 34,44 vs 13,15 ; compare 33,40 vs 1 , 14,23 ; compare $35,38,48$ vs $17,21,28$; compare $36,39,42$ vs $8,12,31$ ). These results suggest that postinjury fields were qualitatively similar in size to normal fields.

Beside the typical fields described above, large receptive fields were infrequently seen in all groups (e.g., Fig. 12D, field 9). In addition, "mixed" receptive fields spanning hairy and glabrous skin are occasionally seen in normal monkeys (e.g., Fig. 13, field 17), but were not seen after injury. It is possible that such fields lost their glabrous component and became smaller after injury, however, because mixed fields are infrequent, the incidence of such changes would be minor.

Inputs from the forelimb and face. A goal of the preinjury mapping was to define carefully, in each monkey, the medial and lateral borders of the hand cortex with the respective adjacent representations of the forelimb and face. Given these preinjury borders, it was possible to test if forelimb and face inputs also moved into the deprived hand cortex or, alternatively, if there were anisotropies in reorganization of these dif- 


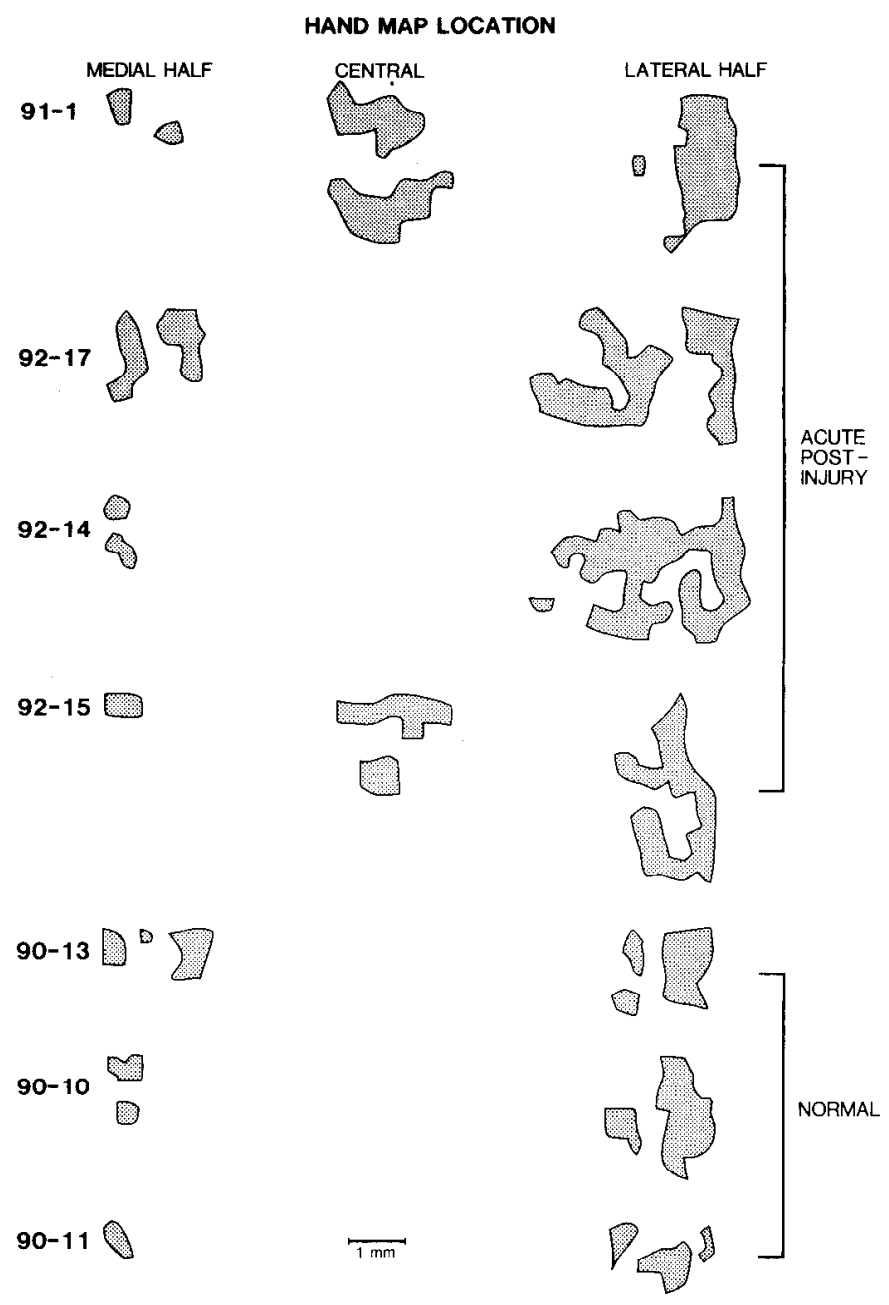

Figure 6. Iocation and size analyses of individual cortical area $3 \mathrm{~b}$ patches with radial nerve inputs in squirrel monkeys. Top, Cortical patches from four postinjury monkeys are grouped according to whether patches were centered within the medial (left) or lateral (right) half of the hand map. Patches centered in central map locations are also indicated (middle). Bottom, Cortical patches from three normal squirrel monkeys grouped as above. Note that (1) larger patches tend to be located laterally and centrally after injury, (2) postinjury lateral patches tend to be larger than normal lateral patches, and (3) postinjury and normal medial patches are similar in size. Scale bar applies to all patches.

ferent inputs. With respect to forelimb inputs, in squirrel monkeys there was a consistent appearance of one or two small medial patches with forelimb inputs following injury (Fig. 3, hatching). These forelimb patches occupied areas ranging from $2 \%$ to $10 \%$ of the hand map (mean $=5 \% ; \mathrm{SD}-3.6 ; N-4$ ) and, thus, were smaller than changes in hand patches. A similar movement of forelimb inputs into the medial hand cortex was not detected in the one completely mapped marmoset monkey (Fig. 4).

Beside a medial representation of the forelimb, marmosets also have a representation of the forelimb and shoulder, referred to as the forequarter, bordering the posterior-lateral hand cortex (e.g., Fig. 4, hatching). In normal marmosets, this representation occupies an area equaling $1-8 \%$ of the hand cortex area (Wall et al., 1992a). In the postinjury map of the one completely mapped marmoset, this representation occupied an area equal to $8 \%$ of the hand cortex and, thus, appeared normal.

Notable postinjury extensions of face inputs into the hand cortex were not seen (Fig. 14). Despite various degrees of apparent reorganization of radial nerve patches in the vicinity of the face representation (e.g., Figs. 3, 4), the postinjury face border varied nonsystematically in close proximity to the preinjury border (Fig. 14).

Taken together, the above results clearly suggest there are anisotropies in the capacities of uninjured inputs from the hand, forelimb, and face to expand into the hand cortex acutely after median and ulnar nerve injury.

Unresponsive cortical zones. Cortical neurons in areas ranging from $50 \%$ to $69 \%$ of the preinjury hand map $($ mean $=58 \%$; SD $=8.3 ; N=4$ ) were unresponsive to tactile inputs following injury in squirrel monkeys. Similarly, in the completely mapped marmoset, neurons spanning $52 \%$ of the map were unresponsive. In all cases, these unresponsive areas were broadly distributed (e.g., Figs. 3, 4), and contrasted sharply with normal and preinjury maps where neurons in all locations were responsive to low-threshold inputs from the hand. Thus, median-ulnar nerve section clearly resulted in an immediate, major deprivation of suprathreshold activation to neurons in some parts of the area $3 \mathrm{~b}$ hand map. These findings indicate that ascending convergence-divergence is insufficient to allow residual hand, forelimb, and face inputs immediate access to all parts of the deprived hand cortex.

\section{Discussion}

Present findings

The preinjury findings indicate that each cortex was normal in terms of the size of the hand map, rough somatotopy, receptive field sizes, and initial responsiveness to inputs from the three hand nerves. The main postinjury findings were as follows. (1) Within minutes after median and ulnar nerve injury, radial nerve dominance aggregates began to undergo an overall twoto threefold expansion. (2) This expansion is not associated with adjustments in the radial nerve skin territory but, rather, is due to decreased central compression of radial inputs. (3) The largest changes occur in lateral and central hand map locations, where individual patches undergo compression decreases to one-third to one-tenth of normal levels. (4) Decompressed radial patches occupy cortical zones that, prior to injury, were activated by inputs from digit, palm, and dorsal hand locations. (5) The postinjury receptive fields are normal in size, but not location. (6) Beside changes in radial nerve inputs from the hand, in squirrel monkeys there is a small expansion of forelimb inputs into hand cortex. (7) In contrast, face inputs do not expand into the hand map. (8) Finally, cortical neurons in $50-69 \%$ of the hand map remain unresponsive to cutaneous stimuli up to 10 hr after this injury.

The overall pattern of rapid reorganization from the above adjustments was highly consistent across different individuals. Given previous indications of individual variability in normal and postinjury somatotopic organization in the hand map (Merzenich et al., 1983a,b, 1987; and see below), this consistency is surprising. However, recent findings indicate that the median, ulnar, and radial nerves provide dominant inputs to aggregates of neurons in the cortical hand map and, normally, there is a high degree of consistency in the size and distribution of these aggregates across individuals (Wall et al., 1993). As discussed below, it appears that the observed consistency in reorganization is related to the consistency in the organization of the normally expressed and unexpressed central connections of the hand nerves. 

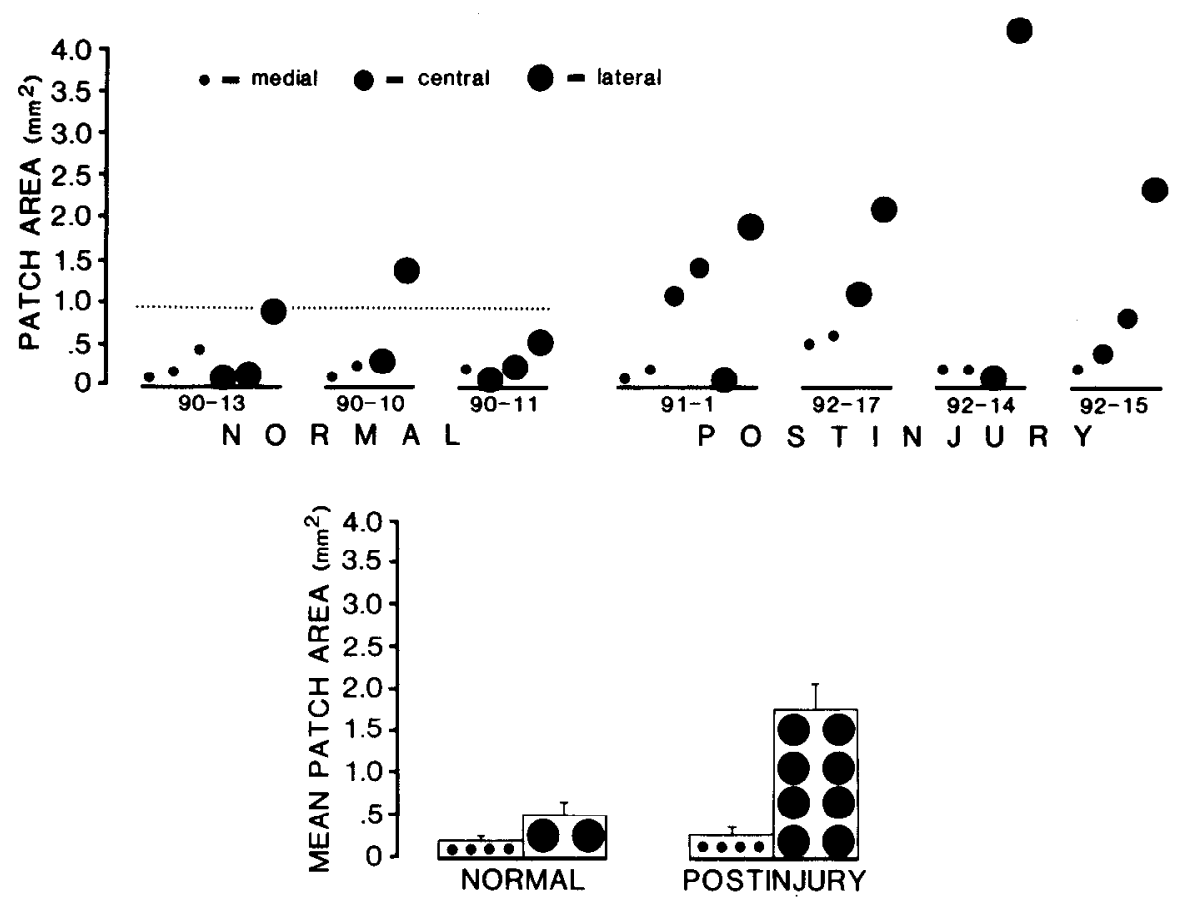

Figure 7. Quantitative analyses of individual patch size in squirrel monkeys. $T o p$, The sizes of individual cortical patches are shown for normal (left) and postinjury (right) maps. Patches located in medial, lateral, and central positions are distinguished for each map (e.g., see Fig. 6). The broken line indicates the upper $95 \%$ confidence limit for all normal patches. Note that (1) the largest patch in each postinjury monkey is larger than the largest patch in any normal monkey, and (2) each postinjury map contains one to three patches near or above the normal $95 \%$ confidence interval. Bottom, Mean areas $( \pm \mathrm{SE})$ of patches centered in medial (small dots) and lateral (large dots) halves of normal (left) and postinjury (right) hand maps. There was a significant postinjury enlargement of lateral patches $[t(5)=$ $3.312, p<0.05]$, but no difference in medial patches $[t(5)=0.617, \mathrm{NS}]$.

\section{Previous studies of acute central changes after nerve injury}

Over the past decade, a clear consensus has emerged that the somatosensory cortex of primates undergoes reorganization after peripheral injuries of the hand (Kaas et al., 1983; Merzenich, 1987; Merzenich et al., 1988, 1990; Wall, 1988; Wall et al., 1990; Calford and Tweedale, 1991a; Kaas, 1991). To maximize reorganization, and to model chronic consequences of human injuries, most studies have evaluated organization at relatively long intervals after injury. For example, of approximately 67 primates that have been studied to date in cortical investigations of injuries of hand nerves, most $(93 \%)$ have been evaluated following postinjury periods of several or more weeks (Table 1). In addition, as discussed below, somewhat different aspects of cortical change have been the focus of interest in the few monkeys studied acutely. Consequently, there presently is no clear consensus regarding the events that occur over the first few hours after injury. This presents an important, but little

Table 1. Studies of somatosensory cortical organization after peripheral injuries involving the hand in primates

\begin{tabular}{llll} 
& & & $\begin{array}{l}\text { Number of } \\
\text { primates } \\
\text { studied } \\
\text { acutely after } \\
\text { injurya }\end{array}$ \\
Reference & $\begin{array}{l}\text { Postinjury times } \\
\text { studied }\end{array}$ & $\begin{array}{l}\text { Number of } \\
\text { srimates } \\
\text { studied }\end{array}$ & 0 \\
\hline Paul et al., 1972 & $6.5-10$ months & 6 & 0 \\
Merzenich et al., 1983a & $61-273 \mathrm{~d}$ & 8 & 3 \\
Merzenich et al., 1983b & Acute to $144 \mathrm{~d}$ & 8 & 0 \\
Wall et al., 1983 & $21-568 \mathrm{~d}$ & 5 & 0 \\
Dykes, 1984 & $3.5-9$ months & 2 & 0 \\
Merzenich et al., 1984 & $2-8.5$ months & 8 & 0 \\
Wall et al., 1986 & $76-322$ d & 4 & 0 \\
Wall and Kaas, 1986 & $2.6-2.9$ years & 2 & 0 \\
Allard et al., 1991 & $14-33$ weeks & 3 & 2 \\
Calford and Tweedale, 1991a & Acute & 2 & 0 \\
Garraghty and Kaas, 1991 & $2-5$ months & 3 & 0 \\
Pons et al., 1991 & $>12$ years & 4 & 0 \\
Wall et al., 1992a & $0.4-1.5$ years & 3 & 0 \\
Wall et al., 1992b & $1.4-1.6$ years & 6 & 5 \\
Florence et al., 1994 & $7-13$ months & 3 & 5
\end{tabular}

"Acute studies involve changes occurring within several minutes (Calford and Tweedale, 1991a) or several hours (Merzenich et al., 1983b) after injury. 
A

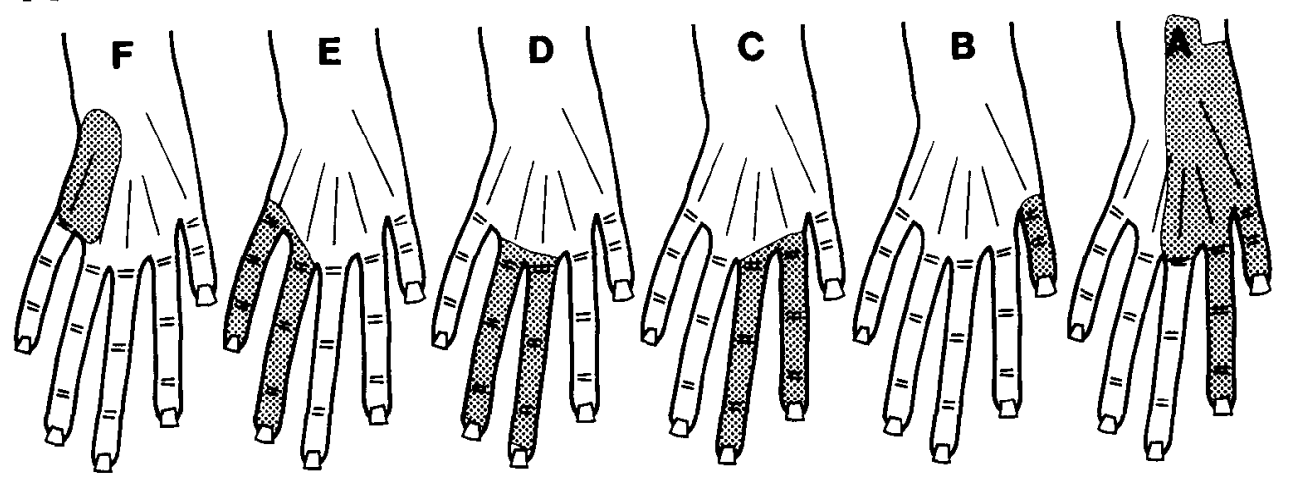

B
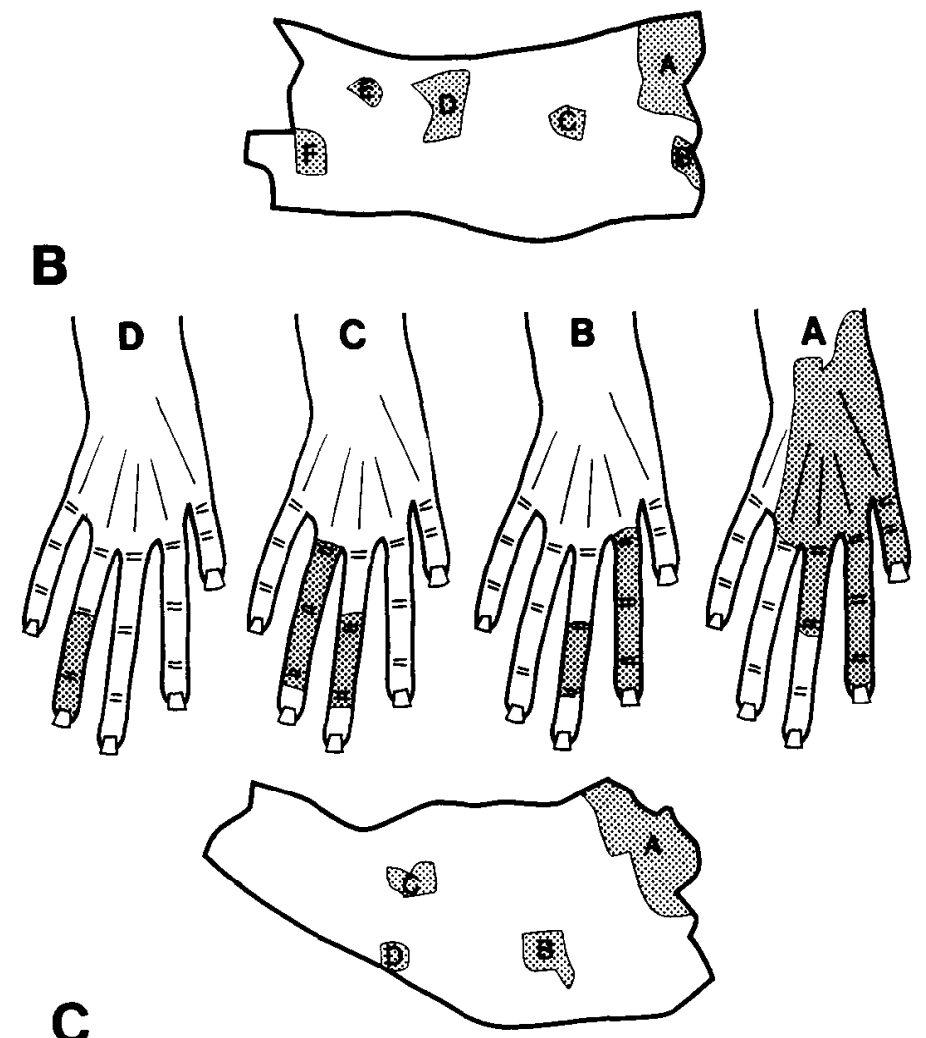

Figure 8 . Skin areas providing inputs to individual cortical patches in three maps from normal squirrel monkeys. As indicated by stippling and letters on hands and cortical maps, subregions of skin in the overall radial nerve territory activated neurons in different cortical patches. Note that (1) skin subregions vary in size from a digit to multiple digits and part of the dorsal hand, (2) shifts in skin subregions from the radial to ulnar side of the hand correspond to rough lateral to medial shifts in cortical patch location, and (3) skin regions associated with different cortical patches overlap somewhat. Orientation applies to all cortical maps. 
A

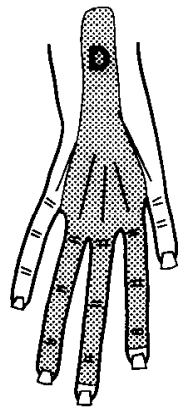

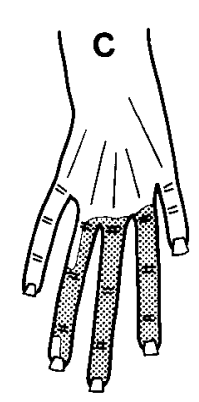
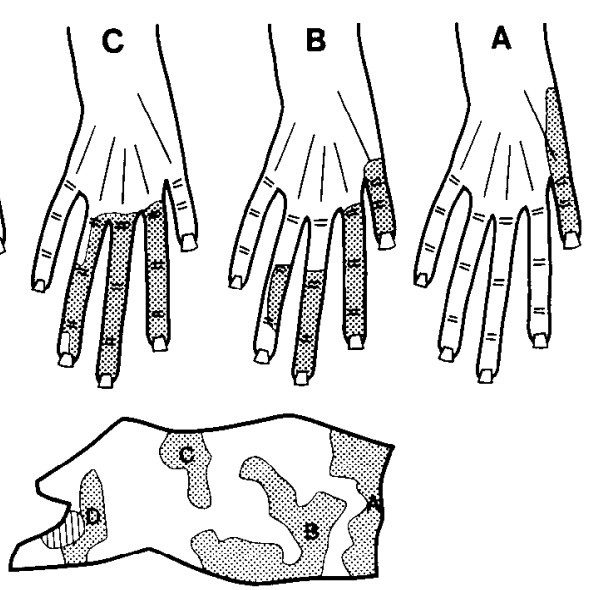

B

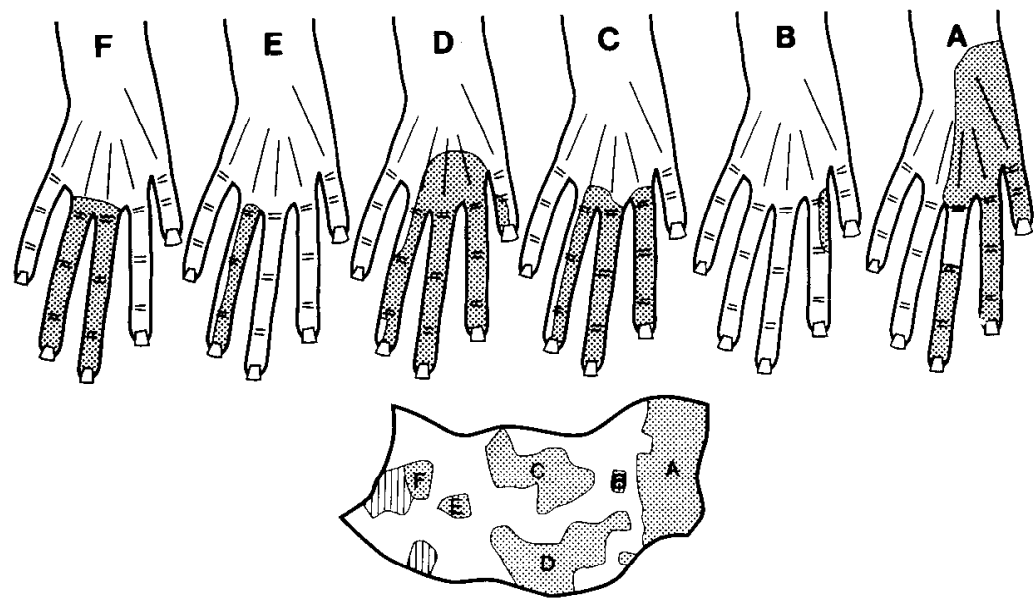

C
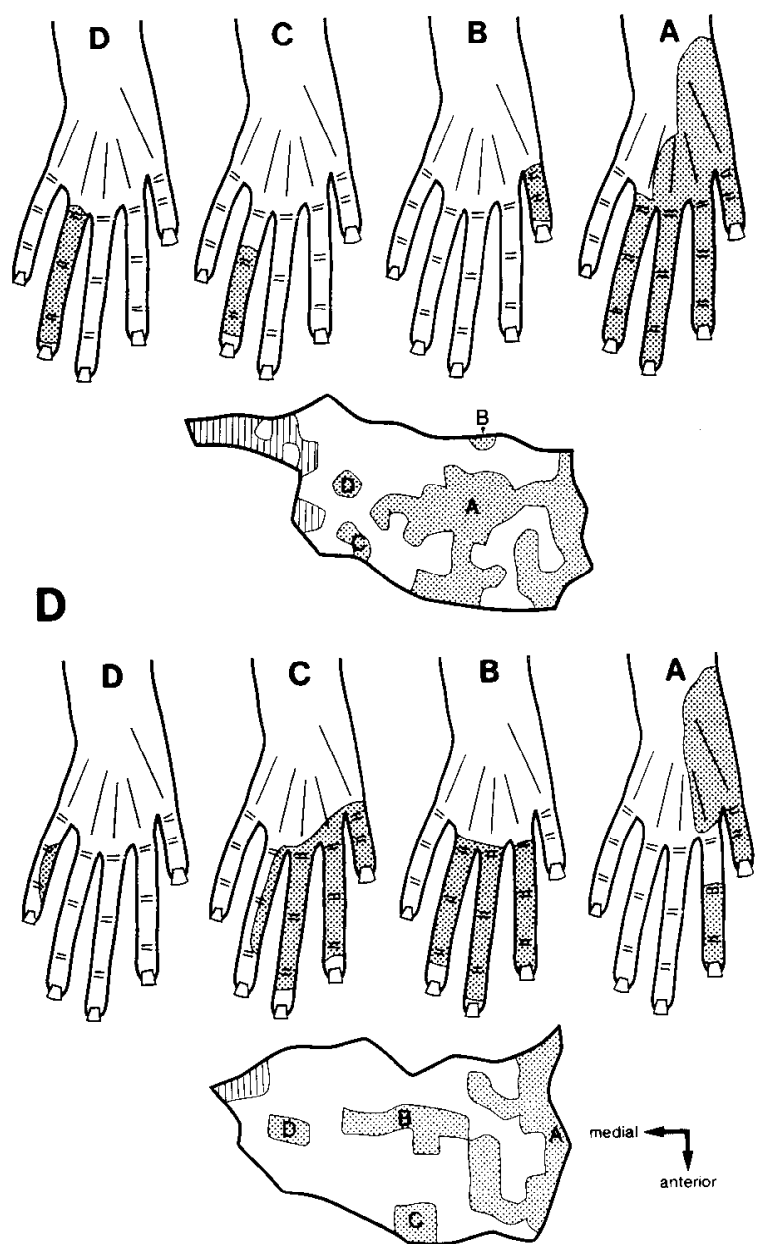

Figure 9. Skin areas providing inputs to individual cortical patches in postinjury maps in four squirrel monkeys. As indicated by stippling and letters on hands and cortical maps, subregions of skin in the overall radial nerve territory activated neurons in different cortical patches. The organizational features of the skin areas associated with these patches were similar to those noted in normal monkeys (e.g., Fig. 8). Hatching indicates regions of the preinjury hand map that became responsive to forelimb inputs following injury. Orientation applies to all cortical maps.

discussed, obstacle to understanding the time course and mechanisms of central changes observed in primates after chronic injury.

Two previous studies in primates have dealt with early cortical changes after nerve injury. Most pertinent is a study of area $3 \mathrm{~b}$ somatotopic organization after acute transection of the median nerve in squirrel and owl monkeys (Merzenich et al., 1983b). This injury, which was less extensive than that in the present study, resulted in the following changes. (1) The representations of parts of the hand with intact inputs underwent little or no immediate changes in size in one monkey (see Fig. 3 in Merzenich et al., 1983b) whereas, in two other individuals, these representations underwent immediate expansions (see Figs. 2 and 7 in Merzenich et al., 1983b). (2) These expansions were delimited to parts of the hand map where glabrous digits were normally represented. (3) There were no expansions of forelimb or face inputs into the hand map. (4) Finally, residual receptive fields were several times larger than normal. The present results confirm the findings that cortical representations of intact hand inputs can expand rapidly, and that inputs from the face do not rapidly move into the hand map. In other respects, the present results differ from the above findings. For example (and see below), the present results indicate that immediate changes were not delimited to preinjury digit representations but, rather, involved neurons that received preinjury inputs from digits, palm, and posterior hand. In addition, in the present study the locations, but not sizes, of receptive fields changed.

In a second study of acute cortical changes in primates, Calford and Tweedale (1991a) analyzed receptive fields in macaque cortical area $3 \mathrm{~b}$ immediately before and after partial amputation of digit 3 in onc monkcy, and after complete amputation of digit 2 in a second monkey. Although not as extensive as the injury in the present study, both amputations resulted in enlargements and/or shifts in the locations of receptive fields. Although size changes were not measured, the differences in the illustrated pre-versus postinjury fields for matched cortical sites appear larger than those seen in the present study (e.g., see Fig. $4 C$ in Calford and Tweedale, 1991 a). Thus, with regard to receptive field size, these findings appear to differ from the present results. Similar to the present findings, some preinjury glabrous receptive fields underwent postinjury shifts in location to hairy skin; moreover, some of these preinjury fields appeared to involve median and/or ulnar nerve territories, and some postinjury fields involved the radial nerve territory. In further agree- 
Figure 10. Analyses of the size of the skin areas associated with individual cortical patches. Top, Sizes of skin areas related to each cortical patch seen in three normal (left) and four postinjury (right) maps. Skin areas are expressed as a percentage of the total skin area of the hand. Skin areas associated with cortical patches in medial, lateral, and central map locations are distinguished. For both normal and postinjury conditions, note that the overall range in size of skin areas is similar. Bottom, Mean sizes ( \pm SEs) of skin areas for: all cortical patches (hatching), medial cortical patches (small dots), and lateral cortical patches (large dots) in normal (left) and postinjury (right) maps. There were no statistical differences in the mean sizes of corresponding skin areas in normal and postinjury maps (see Results).
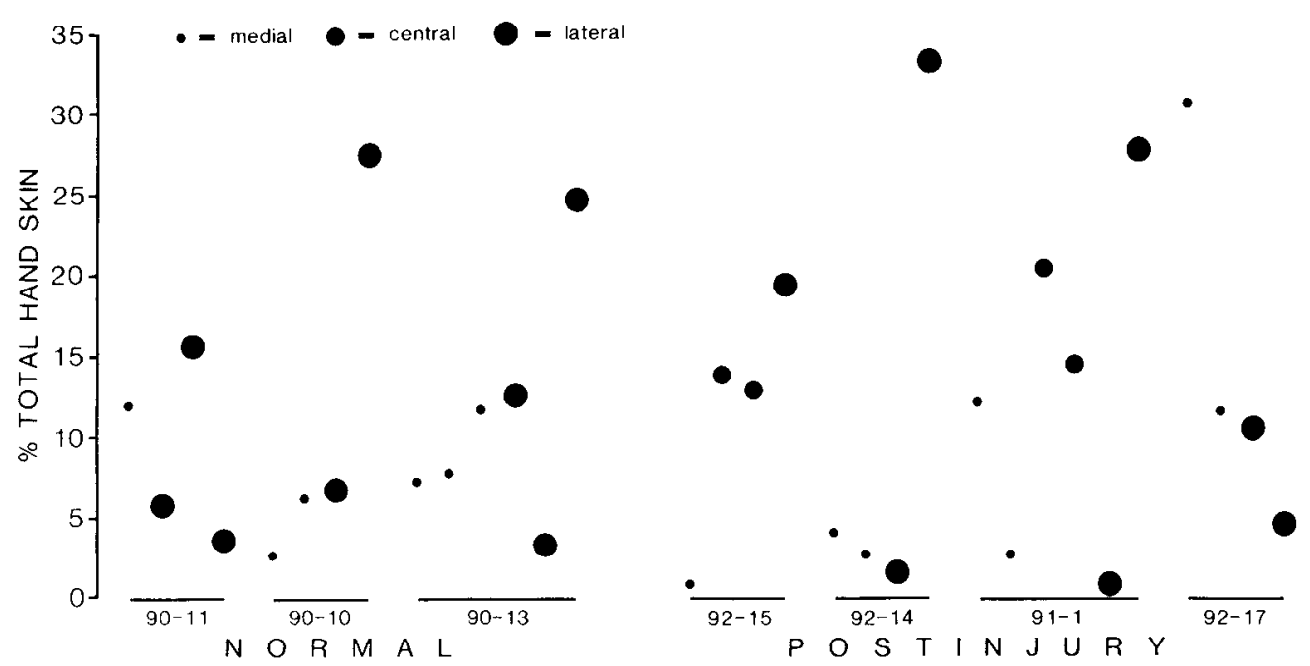

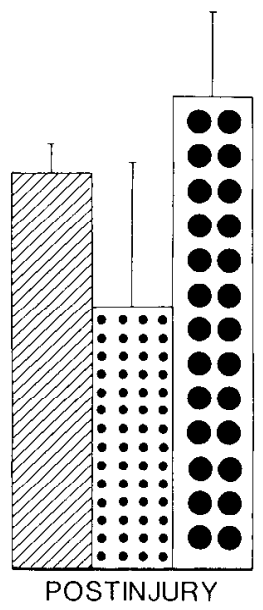

ment with the present findings, the earliest shifts were observed within the first minutes after injury. Efforts were not directed at evaluating the extent or locations of cortex showing these changes, so comparison with the present results is not possible in terms of map changes.

Taken together, the present and previous studies in primates indicate that cortical organization rapidly changes within minutes following hand injury. There also appears to be a difference in findings regarding changes in receptive field size. Although the factors for this difference remain unclear, it seems likely that different patterns of central sensitization caused by the different injuries is important (see below). Finally, the present results provide insight into issues left unresolved in previous primate studies. Specifically, the present findings provide (1) clear indications of the potential high degree of consistency in immediate changes following a particular injury in different individuals, (2) an understanding of the extent and locations of early changes in the radial nerve dominance system, and (3) a clear demonstration of anisotropies in rapid reorganization of inputs from the hand, forelimb, and face.

Consistent with the above conclusions, it is clear that cortical reorganization occurs in nonprimates after peripheral injury, and that the earliest changes also occur within minutes to hours after injury (e.g., Rasmusson and Turnbull, 1983; Kelahan and Doetsch, 1984; Cusick et al., 1990; Turnbull and Rasmuson, 1990; Byrne and Calford, 1991; Calford and Tweedale, 1991a- c). Further studies in both nonprimates and primates indicate that rapid (minutes to hours) changes are not restricted to cortex, but also occur subcortically (e.g., Dostrovsky et al., 1976; Millar et al., 1976; Jacquin et al., 1984; Woolf and King, 1990; Dougherty and Willis, 1992). Thus, explanations of early cortical changes must accommodate the fact that rapid changes occur simultaneously at multiple levels of the somatosensory neuraxis.

\section{Conclusions regarding the neural substrates for the cortical changes seen in the present study}

The time course and nature of the present changes are pertinent for understanding the underlying neural substrates. First, changes in peripheral substrates do not appear to contribute to these rapid changes. In support of this view, the postinjury innervation territories were similar to normal radial nerve territories. This finding, and the rapidity of the changes indicate peripheral sprouting (e.g., Diamond et al., 1992) is not important. In addition, postinjury receptive fields were normal, and originated from nontraumatized skin. This suggests cortical responses were driven by normal activity from low-threshold afferents from normal skin, rather than abnormal activity of sensitized afferents related to traumatized tissues, as seen after other injuries (e.g., LaMotte, 1984; McMahon and Koltzenburg, 1990; Baumann et al., 1991; Woolf, 1991). Finally, current evidence indicates that peripheral injury does not alter the responsiveness of low-threshold mechanoreceptors innervating adjacent nor- 


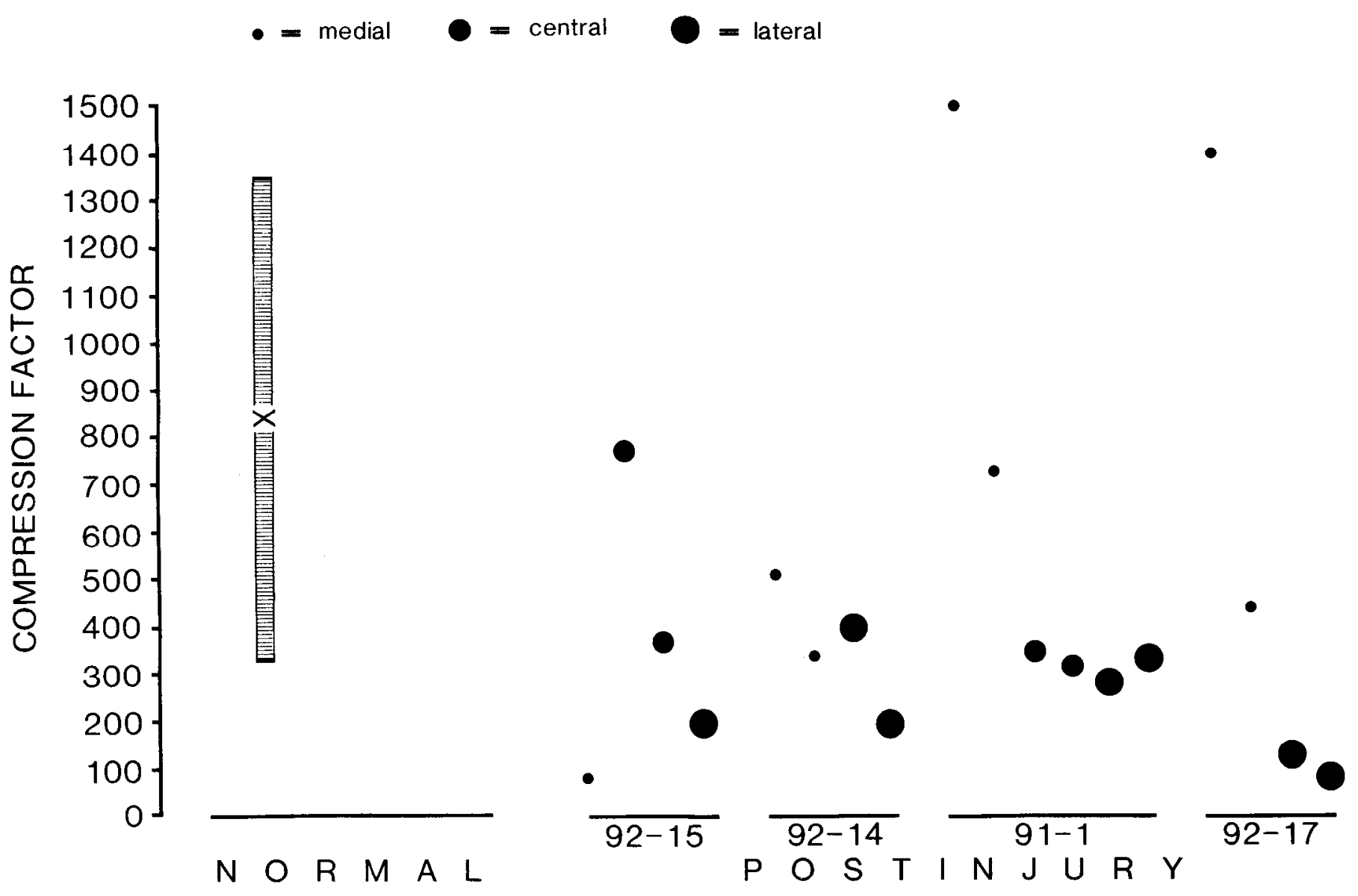

Figure 11. Analysis of compression factors for postinjury cortical patches. The mean $(x)$ and $95 \%$ confidence intervals $($ bars $)$ for the compression factors of patches in normal maps (left) are compared to the compression factors of individual patches in postinjury maps (right). Compression factors for medial, lateral, and central patches are distinguished for the postinjury maps. In each postinjury monkey, the largest compression decreases for individual patches range from about one-third to one-tenth of the normal mean compression. Postinjury maps consistently contain two or more patches with compression factors near or below the normal lower $95 \%$ confidence interval.

mal skin (e.g., Campbell et al., 1988; Woolf, 1989; Baumann et al., 1991; LaMotte et al., 1991). These findings, taken together, suggest the observed changes were not mediated peripherally.

Central substrates focus on two possibilities: (1) circuits formcd after injury as a result of anatomical modification or sprouting of pre- and/or postsynaptic processes, and (2) circuits that existed prior to injury. The present changes have the following relationships to these possibilities. First, although attempts to detect central sprouting have often produced negative findings (e.g., Rodin et al., 1983; Rodin and Kruger, 1984; Seltzer and Devor, 1984; Micevych et al., 1986; Rasmusson and Nance, 1986; McKinley and Kruger, 1988; Pubols and Bowen, 1988; Rasmusson, 1988), other evidence from adult and young mammals indicates injury can induce central modification of preand postsynaptic processes (Goldberger and Murray, 1982; Bernstein and Standler, 1983; Rhoades et al., 1983; Fitzgerald, 1985; Murray and Goldberger, 1986; Sedivec et al., 1986; Molander et al., 1988; LaMotte et al., 1989; Fitzgerald et al., 1990; Shortland et al., 1990; McMahon and Kett-White, 1991; Steward, 1991; Waite and DePermentier, 1991; Woolf et al., 1992; Florence et al., 1993; Rhoades et al., 1993). Detailed time courses for these changes have not been established; however, from the earliest changes reported, a minimum of several days appears required (e.g., Fitzgerald, 1985; Murray and Goldberger,
1986; Woolf et al., 1992). At a more local level, new synapse formation has been reported in the adult hippocampus within minutes after presentation of stimuli that produce long-term potentiation (LTP) (e.g., Lee et al., 1980; Chang and Greenough, 1984; Greenough and Chang, 1988). These findings remain controversial, however, and may be attributable to other explanations (e.g., Desmond and Levy, 1986; Lynch et al., 1988; Geinisman et al., 1991). Although it seems quite feasible that injury discharges accompanying nerve transection could mimic LTP producing stimuli, it appears that reactive synaptogenesis requires postinjury periods of more than a few hours (e.g., Ganchrow and Bernstein, 1981; Nieto-Sampedro and Cotman, 1985; Wells and Tripp, 1987; Steward, 1991). Thus, from current understanding of the time required for postinjury process modification or reactive synaptogenesis, it appears doubtful that the earliest changes in the present study are attributable to formation of new connections. It is worth keeping in mind, however, that a definitive consensus is still emerging on the time course of central structural modifications after peripheral injury.

Working from the existing evidence, it appears that the substrates for the observed changes existed before injury. A corollary of this view is the concept that normal functional organization of somatosensory circuits does not reflect the full response capabilities of the existent anatomical substrates (e.g., 

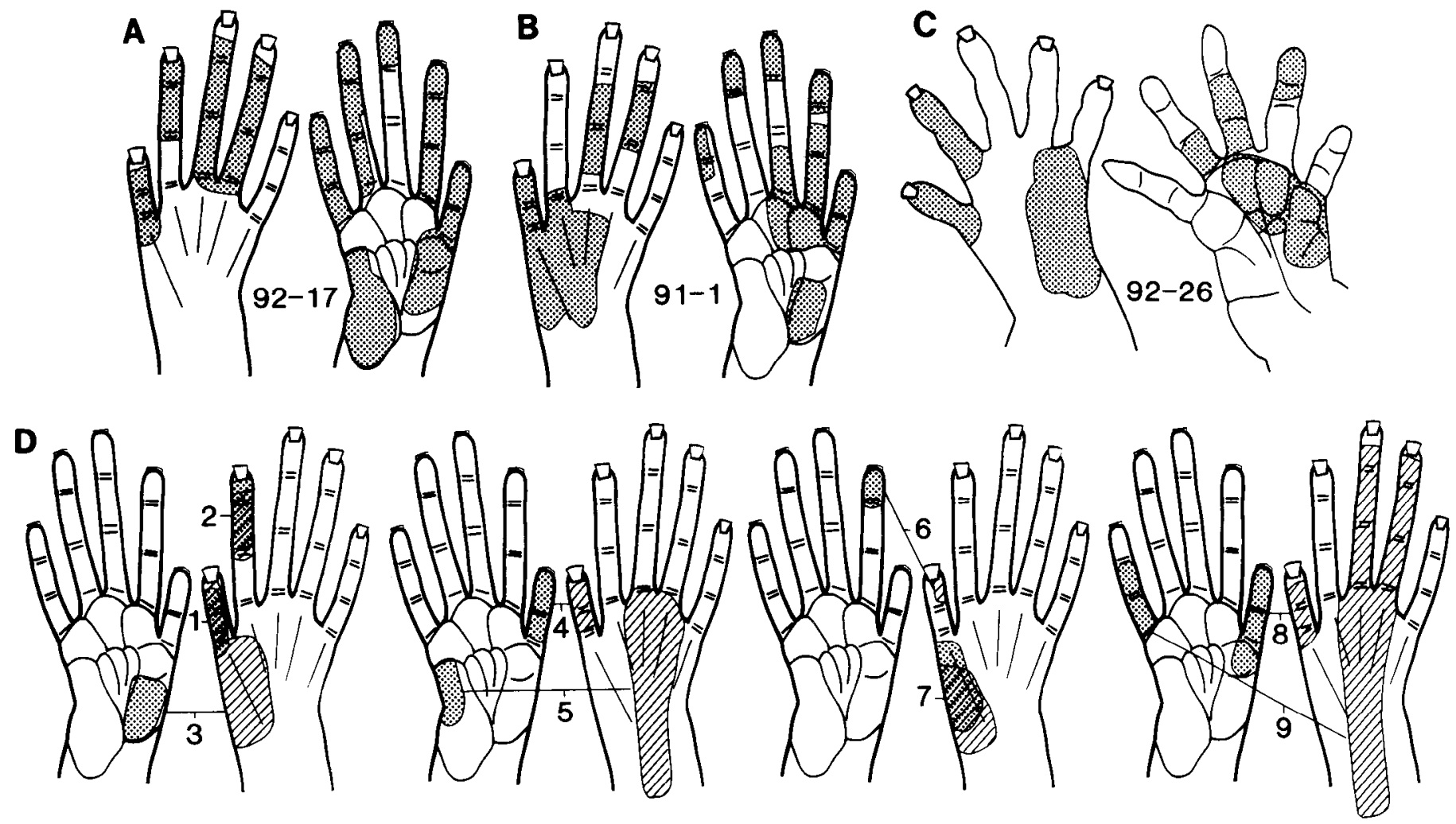

Figure 12. Preinjury inputs to cortical neurons in postinjury radial nerve patches were assessed by two approaches. In the first approach, the receptive fields of all preinjury recording sites located within postinjury radial patches were summed to indicate what preinjury skin areas provided inputs to neurons in postinjury radial patches $(A-C)$. Examples of the summed fields from two squirrel monkeys $(A, B)$ and one marmoset monkey $(C)$ are shown. Similar results were seen in three other squirrel monkeys, and two other marmoset monkeys. $D$, In the second approach, a comparison was made of the receptive fields of preinjury recording sites that were within $0-200 \mu \mathrm{m}$ of a postinjury recording site with a radial nerve receptive field. Examples are shown of preinjury (stippling) and postinjury (hatching) receptive fields for nine pairs (1-9) of recording sites selected from two squirrel monkeys. The shifts in field location seen in these examples are representative of shifts seen in all monkeys. Note that (1) neurons with postinjury responses to radial nerve inputs had preinjury fields on skin innervated by the radial nerve, and on skin innervated by the median and ulnar nerves (e.g., compare $A-C$ with Fig. $2 F$ ), and (2) changes in pre- versus postinjury receptive fields at individual cortical locales varied from little or no shift in fields (e.g., $D$, fields $I$ and 2 ), to small shifts around the surface of one digit (e.g., $D$, fields $4,6,8$ ), to larger shifts around the surface of the hand (e.g., $D$, fields $3,5,9$ ).

Wall, 1977). Evidence supporting this concept includes findings that (1) the skin fields of central somatosensory neurons have subzones, and stimulation to only some of these subzones leads to suprathreshold activation (e.g., Brown et al., 1987; Woolf and King, 1989; Smits et al., 1991), (2) pre- and postsynaptic processes extend into inappropriate or disproportionately large extents of body maps at subcortical and cortical levels of the somatosensory neuraxis (e.g., Wall, 1977; Meyers and Snow, 1984; Devor et al., 1986; Fyffe et al., 1986a,b; Jensen and Killackey, 1987; Snow et al., 1988; Garraghty et al., 1989; Garraghty and Sur, 1990; Florence et al., 1991; Chiaia et al., 1992), (3) normal somatosensory receptive fields are rapidly alterable by exposure to putative transmitters or transmitter agonists and antagonists (e.g., Dykes et al., 1984; Kaneko and Hicks, 1988; Alloway et al., 1989; Dougherty and Willis, 1991; Dubner and Ruda, 1992), and (4) the activation properties of somatosensory neurons are rapidly regulated by extrasensory systems (e.g., McCormick, 1989). Taken together, these findings indicate there are numerous central mechanisms for functional expression of some connections, at the expense of others. Remaining undefined, however, are images of the spatial patterns of distribution of normally expressed and unexpressed central connections for a defined peripheral input.

The present findings provide cortical images of normally ex- pressed and unexpressed radial nerve inputs (e.g., Fig. 15). These findings indicate there is a high degree of individual consistency in arrangement of expressed and unexpressed central substrates of this nerve. In addition, the anisotropies in extents of rapid expansion of hand, forearm, and face inputs indicate there are differences in the arrangement of expressed and unexpressed central substrates between these inputs, and neurons in the cortical hand map. It is important to note that these differences occurred even though each of these inputs have projections that directly abut the deprived median and ulnar nerve cortical dominance bands. This could suggest that preexisting adjacent connectivities, at the cortical level, are not critical for the rapid onset changes seen in the present study. Alternatively, adjacencies in cortical substrates and intracortical connections (e.g., Jones et al., 1978; DeFelipe et al., 1986; Krubitzer and Kaas, 1990) may be important, but there may be differences in the intracortical circuitry between representations of the hand, forelimb, and face.

\section{Conclusions regarding mechanisms for producing the consistent pattern of rapid cortical changes observed in the present study}

Present explanations of reorganization in primate area $3 \mathrm{~b}$ hand cortex propose that changes in use of the hand cause changes 

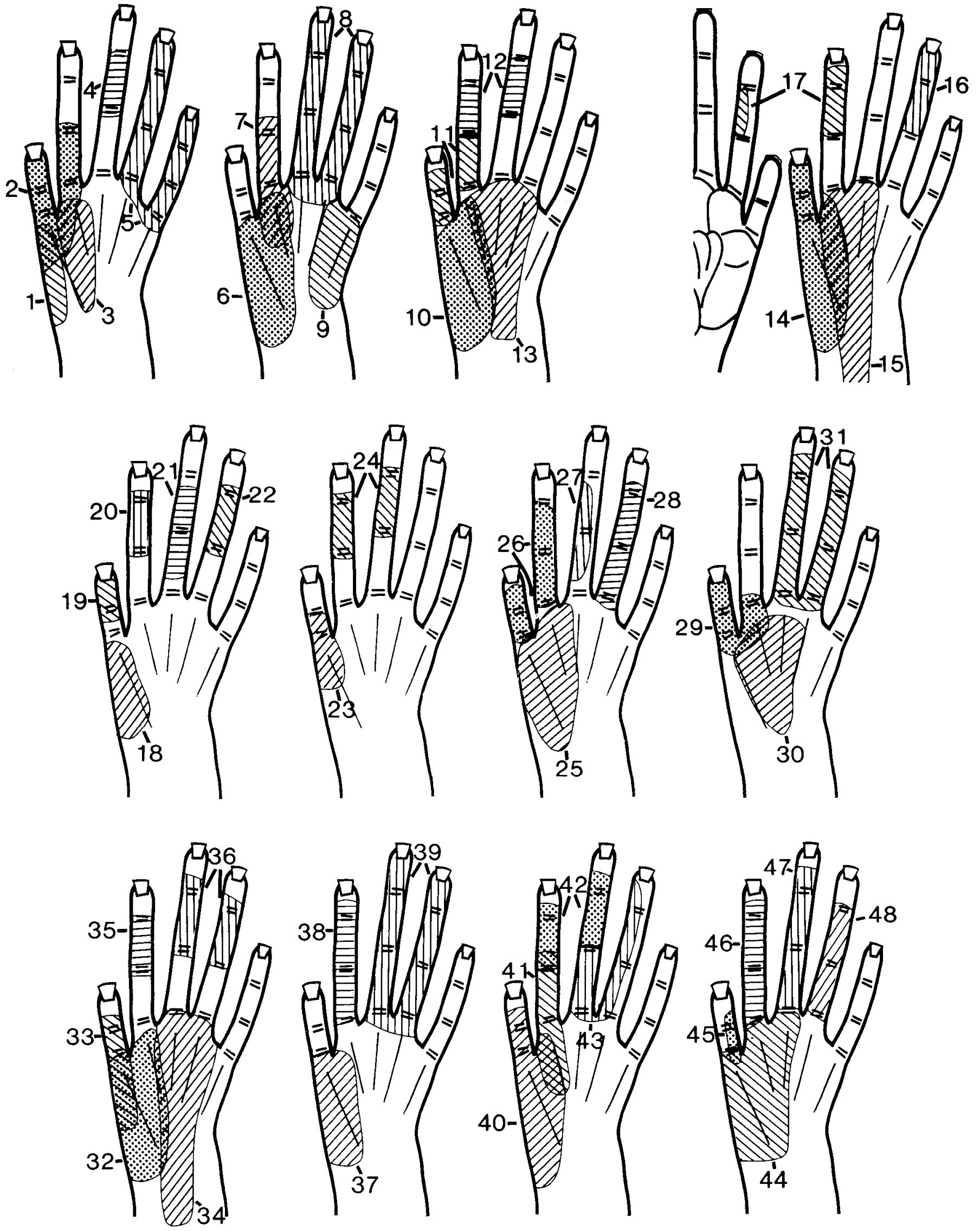

Figure 13. Examples of receptive ficlds involving radial ncrve skin for normal monkcys (top row; Wall ct al., 1993), and for preinjury (middle row) and postinjury (bottom row) conditions in the monkeys in the present study. Some receptive fields involving radial nerve skin may normally extend into other nerve territories (e.g., field 5). As described in the Results, there were no systematic changes in field size across these conditions. 

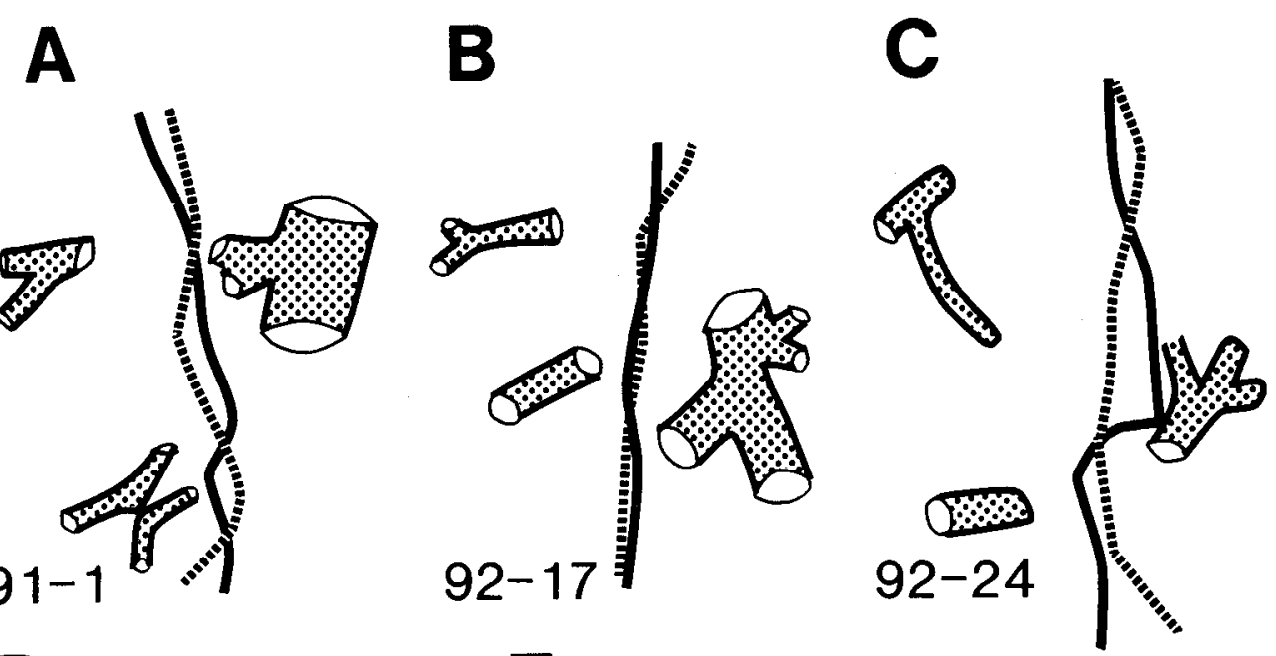

Figure 14. Comparisons of peri-injury borders of the hand and face representations, and of neural aggregates activated by radial nerve hand inputs. $A-D$, Pre- and postinjury borders between the hand and face cortex are indicated for two squirrel monkeys $(A, B)$ and two marmoset monkeys $(C, D)$. Parts of neighboring blood vessels used for orientation in determining these borders are also shown. Note that preinjury (dashed line) and postinjury (solid line) borders vary around each other nonsystematically. $E$, An example of the peri-injury borders of neural aggregates activated by radial nerve inputs from the hand. Note that changes in pre-(dashed line) and postinjury (solid line) borders of these aggregates are larger than the minor, nonsystematic variations in the hand-face border (e.g.,
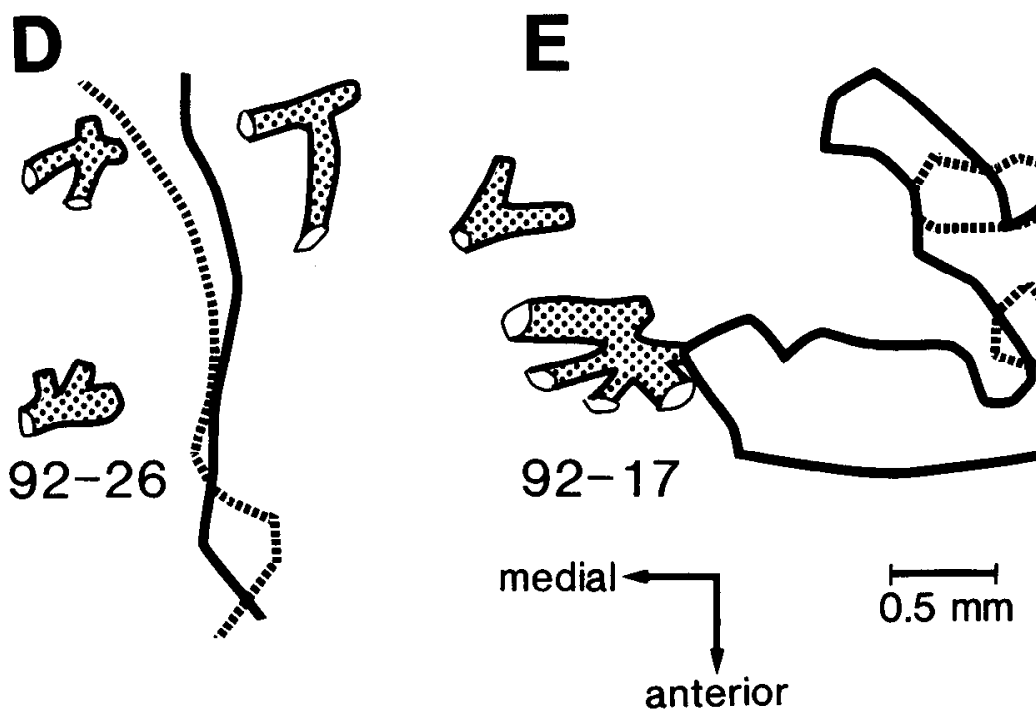

in central temporal correlations of afferent signals from different parts of the hand. These changes in input correlations, in turn, are thought to impact on competition-regulated cortical networks, to produce expansions of cortical networks representing more highly used inputs. This proposal was originally presented to explain cortical reorganization after median nerve injury (Kaas et al., 1983; Merzenich et al., 1983a,b), but has subsequently been generalized to explain variability in normal organization, and changes in organization after a range of chronic somatosensory manipulations, many of which depend on the animal's attention (Merzenich et al., 1984, 1987, 1988, 1990; Merzenich, 1987; Jenkins et al., 1990a,b; Allard et al., 1991; Recanzone et al., 1992a,b). This view has also been incorporated into the neuronal group selection theory, which has modeled how hand inputs are selected, through repetitious use, from a larger repertoire of input connections (e.g., Pearson et al., 1987).

Several observations suggest that the rapid changes seen in the present study required neither use of the hand, nor repetitious use of central connectivity. (1) We did not find idiosyncratic patterns of reorganization of inputs from the hand in different individuals, nor did we find major individual differences in the changes involving hand, face, and forelimb inputs. All monkeys showed similar anisotropies in reorganization for these inputs, and similar quantitative degrees of change for each set of inputs. These consistencies occurred even though the lo-

cations of stimuli, the sequence of stimuli to different locations, and the number of stimuli-that is, the spatial-temporal properties of stimulus barrages-were different in cach monkey. The consistency in cortical change, in the face of idiosyncratic postinjury stimulation, suggests stimulation was not a major factor shaping the observed changes. (2) As rapid postinjury changes occurred, the monkeys were not using their hands for either motor behaviors or sensory feedback of motor behaviors. Moreover, given the dissociative anesthetic effects of ketamine (e.g., Domino, 1990), it is likely the monkeys were incapable of actively attending to stimuli. Thus, attention of the monkey to stimulation, a requirement to produce cortical changes in some use-related conditions, did not appear necessary for the present changes. (3) The earliest changes appeared simultaneously with the first postinjury stimuli. Due to the sequential nature of the postinjury sampling, it is not certain if changes seen during later hours of sampling were, in fact, also fully apparent within minutes after injury. However, initial appearances of the major type of change, that is, replacement of median and ulnar nerve inputs by radial nerve inputs, were clearly established without stimulation, within minutes after injury. (4) Finally, the rapid decompression of radial nerve dominance patches occurred without related decreases in receptive field size. Thus, the inverse relationship between cortical magnification and receptive field size, often associated with use-dependent changes following 

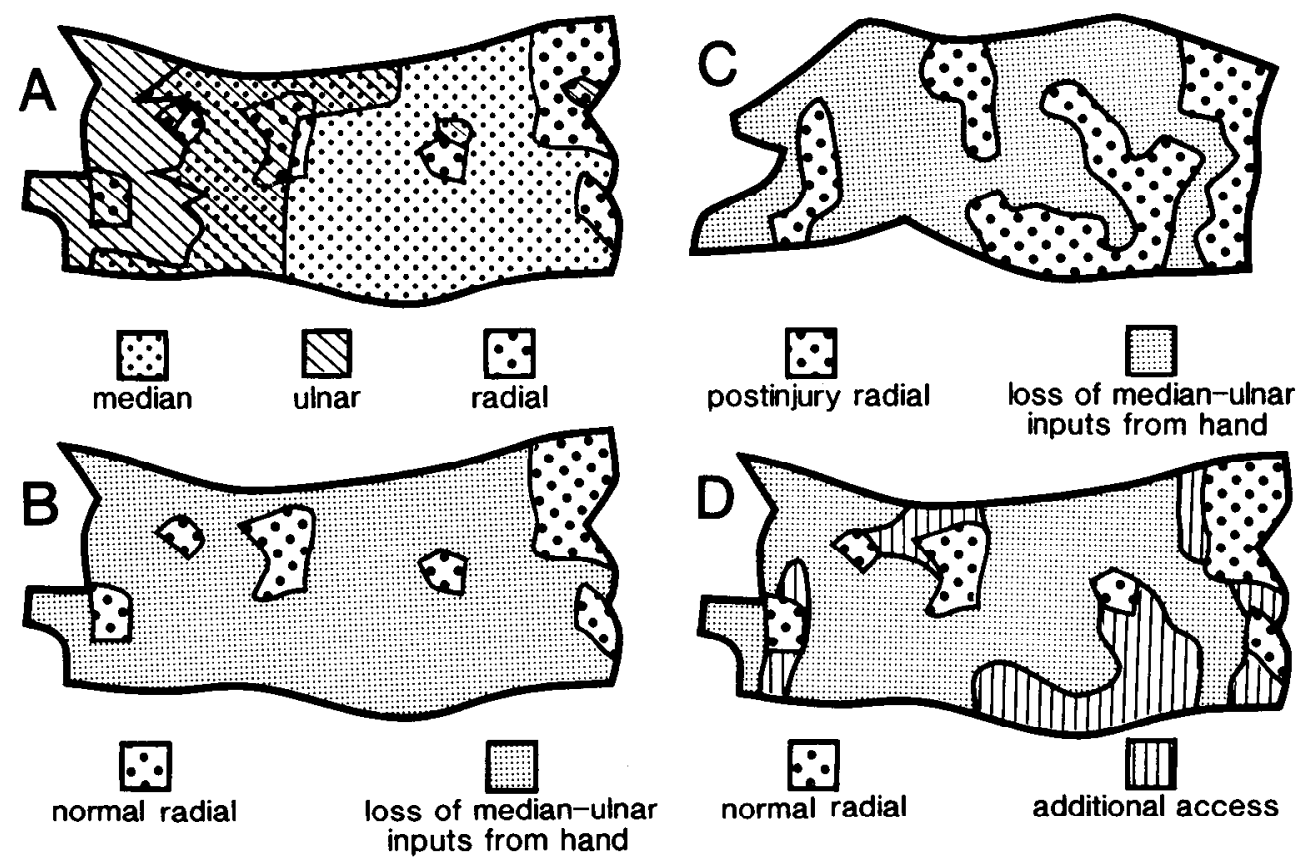

Figure 15. Schematic summary of changes in the cortical expression of radial nerve dominance patches before and after acute injury of the median and ulnar nerves. $A$, Normal nerve dominance patches: an example of the arrangement of cortical dominance zones of the median, ulnar, and radial nerves as defined in a normal monkey (Wall et al., 1993). Cutaneous inputs from the median and ulnar nerves dominate large bandlike aggregates of cortical neurons, whereas inputs from the radial nerve dominate small patchlike aggregates. There is also overlapping of dominant inputs from more than one nerve. $B$, Expected postinjury radial nerve patches: after acute injury of the median and ulnar nerves, only cutaneous inputs from the radial nerve remain intact. Thus, the expectation would be that cortical areas normally dominated by radial nerve inputs (e.g., stippling) would still be apparent, whereas cortical areas normally dominated by median and ulnar nerve inputs would lose responsiveness to cutaneous inputs. The shown radial nerve dominance pattern is based on the normal map shown in $A$, and occupies $15 \%$ of the hand map. Radial nerve dominance patterns from other normal individuals have a similar patchlike arrangement and occupy from $8-15 \%$ of the hand map. $C$, Observed postinjury radial nerve patches: in contrast to the above expectation, following acute median and ulnar nerve injury, patchlike areas occupying from 29 to $41 \%$ of the hand map are dominated by radial nerve inputs. The shown radial nerve dominance pattern is based on one individual in which radial dominance patches occupied $36 \%$ of the hand map. $D$, Additional radial access area: based on the difference in size of radial nerve dominance patches in $B$ and $C$, there appear to be neural substrates by which radial nerve inputs can rapidly access areas of the map that extend beyond the normal radial nerve dominance patches. A hypothetical arrangement of such areas that could cause a pattern like that in $B$ to become more like the pattern in $C$ is indicated (hatching). As described in the Discussion, injury of the median and ulnar nerves appears to result in rapid sensitization and/or decreased suppression in central neuropil which lose median and ulnar nerve inputs (e.g., $B$ ), and rapid access to parts of this neuropil by normally unexpressed radial inputs (e.g., $D$ ).

chronic injuries (e.g., Merzenich et al., 1983a,b, 1984), was not characteristic of the present changes. Taken together, the above arguments suggest that the present changes did not require postinjury use of the hand.

As an alternative to explanations implicating use, two recent proposals appear relevant. First, it has been proposed that digit amputation causes an immediate disruption or loss of spontaneous activity in a population of C-fiber primary afferents (Calford and Tweedale, $1991 \mathrm{a}-\mathrm{c}$ ). Loss of this activity, in turn, is proposed to result in a rapid (within minutes) disruption of chronic central inhibition. This disinhibition putatively raises central excitability, and allows rapid expression of connections that were suppressed before injury. Somewhat different mechanisms have been proposed to explain rapid (within minutes) functional changes in spinal cord neurons after peripheral injuries (e.g., Cook et al., 1987; Woolf, 1989, 1991; Woolf and King, 1990; Baumann ct al., 1991; LaMotte et al., 1991; Simone et al., 1991; Dougherty and Willis, 1992; Dubner and Ruda, 1992; Sorkin et al., 1992). In these proposals, peripheral lesions result in immediate activation of specific C-fiber afferents that, in turn, results in a rapid co-release of peptides and amino acids from the central terminals of afferents. Increased release of these transmitters or modulators is proposed to produce long-lasting depolarization of interncurons and projection ncurons in the spinal cord. Increased depolarization and activation of second messenger systems sensitizes these neurons and, thus, enhances expression of normally unexpressed inputs to these neurons.

Explanations involving sensitization or diminished suppression are attractive in being able to account for many of the present findings. In being triggered by injury, rather than subsequent postinjury use, such mechanisms explain how the observed cortical changes occurred in such short times. In considering these mechanisms, it is also important to recall that neurons across $50-69 \%$ of the hand map remained unresponsive to cutaneous stimulation. Given this fact, sensitization and/or diminished suppression must act to counterbalance central deactivation resulting from loss of inputs. To account for the observed consistent pattern of changes (e.g., Figs. 3, 15B,C), it appears that deactivation, sensitization, and disinhibition are triggered in specific patterns across existing central substrates of the intact and injured nerves.

It appears that cortical changes after hand nerve injury in adult primates involve multiple mechanisms. Early-onset changes, like those in the present study, involve rapid mechanisms that appear triggered by the injury itself. The present results demonstrate, for the first time, a surprisingly high in- 
dividual consistency in the central map patterns of normally expressed and unexpressed inputs that can be activated by such mechanisms. Further work is needed to relate these rapid activation mechanisms, and use-related mechanisms contributing to reorganization after chronic injuries (e.g., Table 1).

\section{References}

Allard T, Clarke SA, Jenkins WM, Merzenich MM (1991) Reorganization of somatosensory area $3 \mathrm{~b}$ representations in adult owl monkeys after digital syndactyly. J Neurophysiol 66:1048 - 1058 .

Alloway KD, Rosenthal P, Burton H (1989) Quantitative measurements of receptive field changes during antagonism of GABAergic transmission in primary somatosensory cortex of cats. Exp Brain Res 78:514-532.

Baumann TK, Simone DA, Shain CN, LaMotte RH (1991) Neurogenic hyperalgesia: the search for the primary cutaneous afferent fibers that contribute to capsaicin-induced pain and hyperalgesia. J Neurophysiol 66:212-227.

Bernstein JJ, Standler NA (1983) Dendritic alteration of rat spinal motoneurons after dorsal horn mince: computer reconstruction of dendritic fields. Exp Neurol 82:532-540.

Brown AG, Koerber HR, Noble R (1987) An intracellular study of spinocervical tract cell responses to natural stimuli and single hair afferent fibres in cats. J Physiol (Lond) 382:331-354

Byrne JA, Calford MB (1991) Short-term expansion of receptive fields in rat primary somatosensory cortex after hindpaw digit denervation. Brain Res 565:218-224.

Calford MB, Tweedale R (1991a) Immediate expansion of receptive fields of neurons in area $3 \mathrm{~b}$ of macaque monkeys after digit denervation. Somatosens Mot Res 8:249-260.

Calford MB, Tweedale R (1991b) C-fibres provide a source of masking inhibition to primary somatosensory cortex. Proc R Soc Lond [Biol] 243:269-275.

Calford MB, Tweedale R (1991c) Acute changes in cutaneous receptive fields in primary somatosensory cortex after digit denervation in adult flying fox. J Neurophysiol 65:178-187.

Campbell JN, Khan AA, Meyer RA, Raja SN (1988) Responses to heat of C-fiber nociceptors in monkey are altered by injury in the receptive field but not by adjacent injury. Pain 32:327-332.

Chang FLF, Greenough WT (1984) Transient and enduring morphological correlates of synaptic activity and efficacy change in the rat hippocampal slice. Brain Res 309:35-46.

Chiaia NL, Bauer WR, Zhang S, King TA, Wright PC, Hobler SC, Freeman KA (1992) Effects of neonatal transection of the infraorbital nerve upon the structural and functional organization of the ventral posteromedial nucleus in the rat. J Comp Neurol 326:561579.

Cook AJ, WoolfCJ, Wall PD, McMahon SB (1987) Dynamic receptive field plasticity in rat spinal cord dorsal horn following C.-primary afferent input. Nature 325:151-153.

Cusick CG, Wall JT, Whiting JH, Wiley RG (1990) Temporal progression of cortical reorganization following nerve injury. Brain Res 537:355-358.

DeFelipe J, Conley M, Jones EG (1986) Long-range focal collateralization of axons arising from corticocortical cells in monkey sensorymotor cortex. J Neurosci 6:3749-3766.

Desmond NL, Levy WB (1986) Changes in the numerical density of synaptic contacts with long-term potentiation in the hippocampal dentate gyrus. J Comp Neurol 253:466-475.

Devor M, Basbaum AI, Seltzer Z (1986) Spinal somatotopic plasticity: possible anatomical basis for somatotopically inappropriate connections. In: Development and plasticity of the mammalian spinal cord (Goldberger ME, Gorio A, Murray M, eds), pp 211-225. New York: Springer.

Diamond J, Gloster A, Kitchener P (1992) Regulation of the sensory innervation of skin: trophic control of collateral sprouting. In: Sensory neurons (Scott SA, ed), pp 309-332. New York: Oxford UP.

Domino EF (1990) Status of ketamine in anesthesiology. Ann Arbor, MI: NPP.

Dostrovsky JO, Millar J, Wall PD (1976) The immediate shift of afferent drive of dorsal column nucleus cells following deafferentation: a comparison of acute and chronic deafferentation in gracile nucleus and spinal cord. Exp Neurol 52:480-495.
Dougherty PM, Willis WD (1991) Modification of the responses of primate spinothalamic neurons to mechanical stimulation by excitatory amino acids and an $N$-methyl-D-aspartate antagonist. Brain Res 542:15-22.

Dougherty PM, Willis WD (1992) Enhanced responses of spinothalamic tract neurons to excitatory amino acids accompany capsaicininduced sensitization in the monkey. J Neurosci 12:883-894.

Dubner R, Ruda MA (1992) Activity-dependent neuronal plasticity following tissue injury and inflammation. Trends Neurosci 15:96103.

Dykes RW (1984) Central consequences of peripheral nerve injuries. Ann Plastic Surg 13:412-422.

Dykes RW, Landry P, Metherate R, Hicks TP (1984) Functional role of GABA in cat primary somatosensory cortex: shaping receptive fields of cortical neurons. J Neurophysiol 52:1066-1093.

Fitzgerald M (1985) The sprouting of saphenous nerve terminals in the spinal cord following early postnatal sciatic nerve section in the rat. J Comp Ncurol 240:407-413.

Fitzgerald M, Woolf CJ, Shortland P (1990) Collateral sprouting of the central terminals of cutaneous primary afferent neurons in the rat spinal cord: pattern, morphology, and influence of targets. J Comp Neurol 300:370-385.

Florence SL, Wall JT, Kaas JH (1991) Central projections from the skin of the hand in squirrel monkeys. J Comp Neurol 311:563-578.

Florence SL, Garraghty PE, Carlson M, Kaas JH (1993) Sprouting of peripheral nerve axons in the spinal cord of monkeys. Brain Res 601 : 343-348.

Florence SL, Garraghty PE, Wall JT, Kaas JH (1994) Sensory afferent projections and area $3 \mathrm{~b}$ somatotopy following median nerve cut and repair in macaque monkeys. J Neurosci, in press.

Fyffe REW, Cheema SS, Rustioni A (1986a) Intracellular staining study of the feline cuneate nucleus. I. Terminal patterns of primary afferent fibers. J Neurophysiol 56:1268-1283.

Fyffe REW, Cheema SS, Light AR, Rustioni A (1986b) Intracellular staining study of the feline cuneate nucleus. II. Thalamic projecting neurons. J Neurophysiol 56:1284-1296.

Ganchrow D, Bernstein JJ (1981) Bouton renewal patterns in rat hindlimb cortex after thoracic dorsal funicular lesions. J Neurosci Res 6:525-537.

Garraghty PE, Kaas JH (1991) Large-scale functional reorganization in adult monkey cortex after peripheral nerve injury. Proc Natl Acad Sci USA 88:6976-6980.

Garraghty PE, Sur M (1990) Morphology of single intracellularly stained axons terminating in area $3 \mathrm{~b}$ of macaque monkeys. J Comp Neurol 294:583-593.

Garraghty PE, Pons TP, Sur M, Kaas JH (1989) The arbors of axons terminating in middle cortical layers of somatosensory area $3 \mathrm{~b}$ in owl monkeys. Somatosens Mot Res 6:401-411.

Geinisman Y, deToledo-Morrell L, Morrell F (1991) Induction of long-term potentiation is associated with an increase in the number of axospinous synapses with segmented postsynaptic densities. Brain Res 566:77-88.

Goldberger ME, Murray M (1982) Lack of sprouting and its presence after lesions of the cat spinal cord. Brain Res 241:227-239.

Greenough WT, Chang FLF (1988) Plasticity of synapse structure and pattern in the cerebral cortex. In: Cerebral cortex, Vol 7 (Peters A, Jones EG, eds), pp 391-440. New York: Plenum.

Jacquin MF, Mooney RD, Rhoades RW (1984) Altered somatosensory receptive fields in hamster colliculus after infraorbital nerve section and xylocaine injection. J Physiol (Lond) 348:471-492.

Jenkins WM, Merzenich MM, Ochs MT, Allard T, Guic-Robles E (1990a) Functional reorganization of primary somatosensory cortex in adult owl monkeys after behaviorally controlled tactile stimulation. J Neurophysiol 63:82-104.

Jenkins WM, Merzenich MM, Recanzone G (1990b) Neocortical representational dynamics in adult primates: implications for neuropsychology. Neuropsychologia 28:573-584.

Jensen KF, Killackey HP (1987) Terminal arbors of axons projecting to the somatosensory cortex of the adult rat. I. The normal morphology of specific thalamocortical afferents. J Neurosci 7:3529-3543.

Jones EG, Coulter JD, Hendry SHC' (1978) Intracortical connectivity of architectonic fields in the somatic sensory, motor, and parietal cortex of monkeys. J Comp Neurol 181:291-348.

Kaas JH (1991) Plasticity of sensory and motor maps in adult mammals. Annu Rev Neurosci 14:137-167. 
Kaas JH, Merzenich MM, Killackey HP (1983) The reorganization of somatosensory cortex following peripheral nerve damage in adult and developing mammals. Annu Rev Neurosci 6:325-356.

Kaneko T, Hicks TP (1988) Baclofen and $\gamma$-aminobutyric acid differentially suppress the cutaneous responsiveness of primary somatosensory cortical neurons. Brain Res 443:360-366.

Kelahan AM, Doetsch GS (1984) Time-dependent changes in the functional organization of somatosensory cerebral cortex following digit amputation in adult raccoons. Somatosens Res 2:49-81.

Krubitzer LA, Kaas JH (1990) The organization and connections of somatosensory cortex in marmosets. J Neurosci 10:952-974.

LaMotte CC, Kapadia SE, Kocol CM (1989) Deafferentation-induced expansion of saphenous terminal field labeling in the adult rat dorsal horn following pronase injection of the sciatic nerve. J Comp Neurol 288:311-325.

LaMotte RH (1984) Can the sensitization of nociceptors account for hyperalgesia after skin injury? Hum Neurobiol 3:47-52.

LaMotte RH, Shain CN, Simone DA, Tsai EP (1991) Neurogenic hyperalgesia: psychophysical studies underlying mechanisms. J Neurophysiol 66:190-211.

Lee KS, Schottler F, Oliver M, Lynch G (1980) Brief bursts of highfrequency stimulation produce two types of structural change in rat hippocampus. J Neurophysiol 44:247-258.

Lynch G, Muller D, Seubert P, Larson J (1988) Long-term potentiation: persisting problems and recent results. Brain Res Bull 21:363372.

McCormick DA (1989) Cholinergic and noradrenergic modulation of thalamocortical processing. Trends Neurosci 12:215-221.

McKinley PA, Kruger L (1988) Nonoverlapping thalamocortical connections to normal and deprived primary somatosensory cortex for similar forelimb receptive fields in chronic spinal cats. Somatosens Res 5:311-323.

McMahon SB, Kett-White R (1991) Sprouting of peripherally regenerating primary sensory ncurones in the adult central nervous system. J Comp Neurol 304:307-315.

McMahon SB, Koltzenburg M (1990) Novel classes of nociceptors: beyond Sherrington. Trends Neurosci 13:199-201.

Merzenich MM (1987) Dynamic neocortical processes and the origins of higher brain functions. In: The neural and molecular bases of learning (Changeux J-P, Konishi M, eds), pp 337-358. New York: Wiley.

Merzenich MM, Kaas JH, Wall JT, Nelson RJ, Sur M, Felleman D (1983a) Topographic reorganization of somatosensory cortical areas $3 \mathrm{~b}$ and 1 in adult monkeys following restricted deafferentation. Neuroscience 8:33-55.

Merzenich MM, Kaas JH, Wall JT, Sur M, Nelson RJ, Felleman D (1983b) Progression of change following median nerve section in the cortical representation of the hand in areas $3 \mathrm{~b}$ and 1 in adult owl and squirrel monkeys. Neuroscience 10:639-665.

Merzenich MM, Nelson RJ, Stryker MP, Cynader MS, Schoppmann A, Zook JM (1984) Somatosensory cortical map changes following digit amputation in adult monkeys. J Comp Neurol 224:591-605.

Merzenich MM, Nelson RJ, Kaas JH, Stryker MP, Jenkins WM, Zook JM, Cynader MS, Schoppmann A (1987) Variability in hand surface representations in areas $3 \mathrm{~b}$ and 1 in adult owl and squirrel monkeys. J Comp Neurol 258:281-296.

Merzenich MM, Recanzone G, Jenkins WM, Allard TT, Nudo RJ (1988) Cortical representational plasticity. In: Neurobiology of neocortex (Rakic P, Singer W, eds), pp 41-67. New York: Wiley.

Merzenich MM, Recanzone GH, Jenkins WM, Nudo RJ (1990) How the brain functionally rewires itself. In: Natural and artificial parallel computations (Arbib MA, Robinson JA, eds), pp 177-210. Cambridge, MA: MIT Press.

Meyers DER, Snow PJ (1984) Somatotopically inappropriate projections of single hair follicle afferent fibres to the cat spinal cord. $J$ Physiol (Lond) 347:59-73.

Micevych PE, Rodin BE, Kruger L (1986) The controversial nature of the evidence for neuroplasticity of afferent axons in the spinal cord. In: Spinal afferent processing (Yaksh TL, ed), pp 417-443. New York: Plenum.

Millar J, Basbaum AI, Wall PD (1976) Restructuring of the somatotopic map and appearance of abnormal neuronal activity in the gracile nucleus after partial deafferentation. Exp Neurol 50:658-672.

Molander C, Kinnman E, Aldskogius H (1988) Expansion of spinal cord primary sensory afferent projection following combined sciatic nerve resection and saphenous nerve crush: a horseradish peroxidase study in the adult rat. J Comp Neurol 276:436-441.

Murray M, Goldberger ME (1986) Replacement of synaptic terminals in lamina II and Clarke's nucleus after unilateral lumbosacral dorsal rhizotomy in adult cats. $\mathbf{J}$ Neurosci 6:3205-3217.

Nieto-Sampedro M, Cotman CW (1985) Growth factor induction and temporal order in central nervous system repair. In: Synaptic plasticity (Cotman CW, ed), pp 407-455. New York: Guilford.

Paul RL, Goodman H, Merzenich M (1972) Alterations in mechanoreceptor input to Brodmann's areas 1 and 3 of the postcentral hand area of Macaca mulatta after nerve section and regeneration. Brain Res 39:1-19.

Pearson JC, Finkel LH, Edelman GM (1987) Plasticity in the organization of adult cerebral cortical maps: a computer simulation based on neuronal group selection. J Ncurosci 7:4209-4223.

Pons TP, Garraghty PE, Ommaya AK, Kaas JH, Taub E, Mishkin M (1991) Massive cortical reorganization after sensory deafferentation in adult macaques. Science 252:1857-1860.

Pubols LM, Bowen DC (1988) Lack of central sprouting of primary afferent fibers after ricin deafferentation. J Comp Neurol 275:282287.

Rasmusson DD (1988) Projections of digit afferents to the cuneate nucleus in the raccoon before and after partial deafferentation. J Comp Neurol 277:549-556.

Rasmusson DD, Nance DM (1986) Non-overlapping thalamocortical projections for separatc forcpaw digits beforc and after cortical rcorganization in the raccoon. Brain Res Bull 16:399-406.

Rasmusson DD, Turnbull BG (1983) Immediate effects of digit amputation on SI cortex in the raccoon: unmasking of inhibitory ficlds. Brain Res 288:368-370.

Recanzone GH, Merzenich MM, Jenkins WM, Grajski KA, Dinse HR (1992a) Topographic reorganization of the hand representation in cortical area $3 \mathrm{~b}$ of owl monkeys trained in a frequency-discrimination task. J Neurophysiol 67:1031-1056.

Recanzone GH, Merzenich MM, Schreiner CE (1992b) Changes in the distributed temporal response properties of SI cortical neurons reflect improvements in performance on a temporally based tactile discrimination task. J Neurophysiol 67:1071-1091.

Rhoades RW, Fiore JM, Math MF, Jacquin MF (1983) Reorganization of trigeminal primary afferents following neonatal infraorbital nerve section in hamster. Dev Brain Res 7:337-342.

Rhoades RW, Wall JT, Chiaia NL, Bennett-Clarke CA, Killackey HP (1993) Anatomical and functional changes in the organization of the cuneate nucleus of adult rats after fetal forelimb amputation. J Neurosci 13:1106-1119.

Rodin BE, Kruger L (1984) Absence of intraspinal sprouting in dorsal root axons caudal to a partial spinal hemisection: a horseradish peroxidase transport study. Somatosens Res 2:171-192.

Rodin BE, Sampogna SL, Kruger L (1983) An examination of intraspinal sprouting in dorsal root axons with the tracer horseradish peroxidase. J Comp Neurol 21 5:187-198.

Sedivec MJ, Capowski JJ, Mendell LM (1986) Morphology of HRPinjected spinocervical tract neurons: effect of dorsal rhizotomy. J Neurosci 6:661-672.

Seltzer Z, Devor M (1984) Effect of nerve section on the spinal distribution of neighboring nerves. Brain Res 306:31-37.

Shortland P, Molander C, Woolf, CJ, Fitzgerald M (1990) Neonatal capsaicin treatment induces invasion of the substantia gelatinosa by the terminal arborizations of hair follicle afferents in the rat dorsal horn. J Comp Neurol 296:23-31.

Simone DA, Sorkin LS, Oh U, Chung JM, Owens C, LaMotte RH, Willis WD (1991) Neurogenic hyperalgesia: central neural correlates in responscs of spinothalamic tract neurons. J Neurophysiol 66:228246.

Smits E, Gordon DC, Witte S, Rasmusson DD, Zarzecki P (1991) Synaptic potentials evoked by convergent somatosensory and corticocortical inputs in raccoon somatosensory cortex: substrates for plasticity. J Neurophysiol 66:688-695.

Snow FJ, Nudo RJ, Rivers W, Jenkins WM, Merzenich MM (1988) Somatotopically inappropriate projections from thalamocortical neurons to the SI cortex of the cat demonstrated by the use of intracortical microstimulation. Somatosens Res 5:349-372.

Sorkin LS, Westlund KN, Sluka KA, Dougherty PM, Willis WD (1992) Neural changes in acute arthritis in monkeys. IV. Time-course of 
amino acid release into the lumbar dorsal horn. Brain Res Rev 17 $39-50$.

Steward O (1991) Synapse replacement on cortical neurons following denervation. In: Cerebral cortex, Vol 9 (Peters A, Jones EG, eds), pp 81-131. New York: Plenum.

Turnbull BG, Rasmusson DD (1990) Acute effects of total or partial digit denervation on raccoon somatosensory cortex. Somatosens Mot Res 7:365-389.

Waite PME, DePermentier P (1991) The rat's postero-orbital sinus hair. I. Brainstem projections and the effect of infraorbital nerve section at different ages. J Comp Neurol 312:325-340.

Wall JT (1988) Variable organization in cortical maps of the skin as an indication of the lifelong adaptive capacities of circuits in the mammalian brain. Trends Neurosci 11:549-557.

Wall JT, Kaas JH (1986) Long-term cortical consequences of reinnervation errors after nerve regeneration in monkeys. Brain Res 372: 400-404.

Wall JT, Felleman DJ, Kaas JH (1983) Recovery of normal topography in the somatosensory cortex of monkeys after nerve crush and regeneration. Science 221:771-773.

Wall JT, Kaas JH, Sur M, Nelson RJ, Felleman DJ, Merzenich MM (1986) Functional reorganization in somatosensory cortical areas $3 \mathrm{~b}$ and 1 of adult monkeys after median nerve repair: possible relationships to sensory recovery in humans. J Neurosci 6:218-233.

Wall JT, Florence SL, Huerta MF, Kaas JH (1990) Functional and morphological aggregation in the somatosensory system of primates and its relevance for central reorganization after peripheral injury. In: Recent achievements in restorative neurology, 3, Altered sensation and pain (Dimitrijevic MR, Wall PD, Lindblom U, eds), pp 165180. Basel: Karger.
Wall JT, IYuerta MF, Kaas JH (1992a) Changes in the cortical map of the hand following postnatal median nerve injury in monkeys: modification of somatotopic aggregates $J$ Neurosci 12:3445-3455.

Wall JT, Huerta MF, Kaas JH (1992b) Changes in the cortical map of the hand following postnatal ulnar and radial nerve injury in monkeys: organization and modification of nerve dominance aggregates. J Neurosci 12:3456-3465.

Wall JT, Nepomuceno V, Rasey SK (1993) Nerve innervation on the hand and associated nerve dominance aggregates in the somatosensory cortex of a primate [squirrel monkey]. J Comp Neurol, in press.

Wall PD (1977) The presence of ineffective synapses and the circumstances which unmask them. Philos Trans R Soc Lond [Biol] 278 . $361-372$.

Wells J, Tripp LN (1987) Time course of reactive synaptogenesis in the subcortical somatosensory systcm. J Comp Neurol 255:466-475.

Woolf CJ (1989) Recent advances in the pathophysiology of acute pain. Br J Anaesth 63:139-146.

Woolf CJ (1991) Generation of acute pain: central mechanisms. Br Med Bull 47:523-533.

Woolf CJ, King EA (1989) Subthreshold components of the cutaneous mechanoreceptive fields of dorsal horn neurons in the rat lumbar spinal cord. J Neurophysiol 62:907-916.

WoolfCJ, King EA (1990) Dynamic alterations in the cutaneous mechanoreceptive fields of dorsal horn neurons in the rat spinal cord. $\mathbf{J}$ Neurosci 10:2717-2726.

Woolf CJ, Shortland P, Coggeshall RE (1992) Peripheral nerve injury triggers central sprouting of myelinated afferents. Nature 355:75-78. 